\title{
The HadCM3 contribution to PlioMIP phase 2
}

\author{
Stephen J. Hunter, Alan M. Haywood, Aisling M. Dolan, and Julia C. Tindall \\ School of Earth and Environment, University of Leeds, Leeds, LS2 9JT, UK \\ Correspondence: Stephen J. Hunter (s.hunter@leeds.ac.uk)
}

Received: 21 December 2018 - Discussion started: 8 January 2019

Revised: 15 August 2019 - Accepted: 20 August 2019 - Published: 13 September 2019

\begin{abstract}
We present the UK's input into the Pliocene Model Intercomparison Project phase 2 (PlioMIP2) using the Hadley Centre Climate Model version 3 (HadCM3). The $400 \mathrm{ppm} \mathrm{CO}_{2}$ Pliocene experiment has a mean annual surface air temperature that is $2.9^{\circ} \mathrm{C}$ warmer than the preindustrial and a polar amplification of between 1.7 and 2.2 times the global mean warming. The Pliocene Research Interpretation and Synoptic Mapping (PRISM4) enhanced Pliocene palaeogeography accounts for a warming of $1.4^{\circ} \mathrm{C}$, whilst the $\mathrm{CO}_{2}$ increase from 280 to $400 \mathrm{ppm}$ leads to a further $1.5^{\circ} \mathrm{C}$ of warming. Climate sensitivity is $3.5^{\circ} \mathrm{C}$ for the pre-industrial and $2.9^{\circ} \mathrm{C}$ for the Pliocene. Precipitation change between the pre-industrial and Pliocene is complex, with geographic and land surface changes primarily modifying the geographical extent of mean annual precipitation. Sea ice fraction and areal extent are reduced during the Pliocene, particularly in the Southern Hemisphere, although they persist through summer in both hemispheres. The Pliocene palaeogeography drives a more intense Pacific and Atlantic meridional overturning circulation (AMOC). This intensification of AMOC is coincident with more widespread deep convection in the North Atlantic. We conclude by examining additional sensitivity experiments and confirm that the choice of total solar insolation (1361 vs. $1365 \mathrm{Wm}^{-2}$ ) and orbital configuration (modern vs. $3.205 \mathrm{Ma}$ ) does not significantly influence the anomaly-type analysis in use by the Pliocene community.
\end{abstract}

\section{Introduction}

The Pliocene Model Intercomparison Project phase 2 (hereafter PlioMIP2; Haywood et al., 2016) has a dual focus: (1) to improve understanding of Pliocene climate and (2) to evaluate climate model uncertainty for a warmer-than-present climate. This dual focus is referred to as Pliocene4Pliocene (P4P) and Pliocene4Future (P4F). PlioMIP2 concentrates on a "time slice" centred on an interglacial peak (Marine Isotope Stage (MIS) KM5c; $3.205 \mathrm{Ma}$ ) within the mid-Piacenzian; for convenience, we refer to this as the Pliocene. The overall PlioMIP2 experiment design is split up into three components - CORE, tier 1 and tier 2 experiments. The CORE components must be completed by all modelling groups, whilst the tier 1 and tier 2 components are optional, with tier 1 experiments being a higher priority than tier 2 . The PlioMIP2 protocol specifies a standard and enhanced boundary condition dataset. The standard boundary conditions have a Pliocene topography constrained by the modern land sea mask (LSM) and bathymetry, whilst the enhanced boundary conditions have full PRISM4 (Pliocene Research Interpretation and Synoptic Mapping) mid-Piacenzian palaeogeography (Dowsett et al., 2016). Here, we describe the model setup of the enhanced boundary conditions within HadCM3 (Hadley Centre Climate Model version 3). Table 1 details the PlioMIP2 experiments conducted within this study, along with an additional set of non-PlioMIP2 experiments that explore specific model sensitivities. We conduct all CORE and tier 1 experiments as well as the Pliocene4Future tier 2 experiments as described within Haywood et al. (2016).

The structure of this paper is as follows. Section 2 describes the model configuration. Section 3 describes the experiment design including model boundary conditions, model initialisation and spin-up. Results from the experiments are then described within Sect. 4, with a particular focus on atmospheric circulation and surface climatology (Sect. 4.1) and the oceanic responses (Sect. 4.2). 
Table 1. Summary of simulations conducted within this study. Those in italic represent simulations beyond the PlioMIP2 experiment design.

\begin{tabular}{|c|c|c|c|c|}
\hline No. & ID & Geography & PlioMIP2 component & Description \\
\hline 1 & Eoi $^{400}$ & Pliocene & CORE & $\begin{array}{l}\text { Full enhanced boundary conditions with fixed } \\
\text { vegetation and } 400 \mathrm{ppm} \mathrm{CO}_{2}\end{array}$ \\
\hline 2 & Eoi $^{450}$ & Pliocene & $\mathrm{T} 1 \mathrm{P} 4 \mathrm{~F} \& \mathrm{P} 4 \mathrm{P}$ & As Eoi ${ }^{400}$ but with $450 \mathrm{ppm} \mathrm{CO}_{2}$ \\
\hline 3 & Eoi $^{350}$ & Pliocene & T1 P4F \& P4P & As Eoi ${ }^{400}$ but with $350 \mathrm{ppm} \mathrm{CO}_{2}$ \\
\hline 4 & Eoi $^{280}$ & Pliocene & T2 P4F \& P4P & As Eoi ${ }^{400}$ but with $280 \mathrm{ppm} \mathrm{CO}_{2}$ \\
\hline 5 & $E^{280}$ & PI & CORE & $\begin{array}{l}\text { Standard pre-industrial boundary conditions } \\
\text { with fixed vegetation and } 280 \mathrm{ppm} \mathrm{CO}_{2}\end{array}$ \\
\hline 6 & $E^{400}$ & PI & $\mathrm{T} 2 \mathrm{P} 4 \mathrm{~F} \& \mathrm{P} 4 \mathrm{P}$ & As $\mathrm{E}^{280}$ but with $400 \mathrm{ppm} \mathrm{CO}_{2}$ \\
\hline 7 & $E^{560}$ & PI & T1 P4F & As $\mathrm{E}^{280}$ but with $560 \mathrm{ppm} \mathrm{CO} 2$ \\
\hline 8 & orb Eoi 400 & Pliocene & Additional sensitivity & As Eoi ${ }^{400}$ but with $3.205 \mathrm{Ma}$ orbit (KM5c) \\
\hline 9 & ${ }_{1361}$ Eoi $^{400}$ & Pliocene & Additional sensitivity & As Eoi ${ }^{400}$ but with TSI of $1361 \mathrm{Wm}^{-2}$ \\
\hline 10 & ${ }_{1361} E^{280}$ & PI & Additional sensitivity & As $\mathrm{E}^{280}$ but with TSI of $1361 \mathrm{Wm}^{-2}$ \\
\hline
\end{tabular}

The following definitions are used: pre-industrial (PI), tier 1 (T1), tier 2 (T2), Pliocene for Future (P4F), Pliocene for Pliocene (P4P) and total solar irradiance (TSI).

\section{Model description}

We use the UK Meteorological Office (UKMO) HadCM3 coupled atmosphere-ocean general circulation model (AOGCM). A top-level description of the atmosphere and ocean models relevant to this palaeogeographic reconfiguration follows. Focus is given to the ocean model, as its external geometry is changed (the atmosphere model layers drape over the topography) and certain aspects impact upon the interpretation of model prediction. For a more comprehensive description of the fundamental model structure, see Pope et al. (2000) and Gordon et al. (2000). Subsequent corrections and improvements to the model, as well as a thorough evaluation against observational data, have been described in Valdes et al. (2017). The HadCM3 model used in this study is equivalent, in terms of model updates and modifications, to HadCM3B-M2.1a of Valdes et al. (2017). We keep with the name HadCM3 in reference to the UKMO (Pope et al., 2000; Gordon et al., 2000) but acknowledge the contribution made by the University of Bristol in keeping the HadCM3 model developed and updated.

The HadCM3 climate model is no longer state of the art but the model's runtime speed, relative ease of reconfiguration and prediction performance make it well suited for an ensemble of centennial-scale palaeoclimate simulations as is required here. HadCM3 can be integrated for many thousands of model years and reaches a satisfactory state of equilibrium with little drift in the surface climatology. However, there are a number of model weaknesses, compared to more contemporary models, and these will be discussed where relevant.

The HadCM3 model has been used extensively for studies of the Pliocene. The model was used within PlioMIP1 experiments 1 (atmosphere GCM) and 2 (atmosphere-ocean GCM) (Haywood et al., 2010, 2011; Bragg et al., 2012), and amongst others has been used to successfully investi- gate Panama Seaway closure (Lunt et al., 2008), El NiñoSouthern Oscillation (ENSO) and teleconnections (Bonham et al., 2009), ice sheet reconstructions and orbital forcing (Dolan et al., 2011; Prescott et al., 2014), sea ice reconstructions (Howell et al., 2014), terrestrial and marine oxygen isotopes (Tindall and Haywood, 2015), and non-analogous aspects of Pliocene climate (Hill, 2015). In all cases, either a modern LSM and bathymetry was used or only specific regional palaeogeographical uncertainties were explored. This body of work therefore represents the first published record where HadCM3 has been reconfigured with a bespoke global Pliocene palaeogeography.

\subsection{Atmosphere and land models}

The atmosphere component of HadCM3 has 19 vertical hybrid sigma-pressure levels extending to $5 \mathrm{hPa}$. Horizontal resolution is $3.75^{\circ}$ longitude $\times 2.5^{\circ}$ latitude. The model has a time step of $30 \mathrm{~min}$ and is coupled to the ocean model (Sect. 2.2) at the end of every model day (Gordon et al., 2000). Atmospheric composition, other than $\mathrm{CO}_{2}$ (described in Sect. 3.1 and 3.2), is equivalent to pre-industrial throughout $\left(\mathrm{N}_{2} \mathrm{O} 270 \mathrm{ppb}, \mathrm{CH}_{4} 760 \mathrm{ppb}\right.$ and no $\left.\mathrm{CFCs}\right)$, consistent with both the PMIP2 protocol (the second phase of the Palaeoclimate Model Intercomparison Project; LSCE, 2007; Braconnot et al., 2007) and the previous Pliocene experiments conducted within PlioMIP1. Monthly distribution of ozone is derived from the $\mathrm{Li}$ and Shine (1995) climatology and ground-based troposphere measurements, corrected for the ozone hole (Johns et al., 2003). The radiative effects of background aerosol are represented by a simple parameterisation based on modern climatological conditions (Cusack et al., 1998).

The solar constant (total solar irradiance; hereafter TSI) is held fixed at $1365 \mathrm{Wm}^{-2}$ within all PlioMIP2 protocol experiments, a value consistent with the pre-industrial exper- 
iment within PMIP2 (LSCE, 2007; Braconnot et al., 2007) and CMIP5 (the fifth phase of the Coupled model Intercomparison Project; Taylor et al., 2012) as well as PlioMIP1. This value (derived in the 1990s) is used to remain consistent with previous work, and the authors acknowledge that spaceborne measurements indicate that TSI has decreased from 1371 in 1978 to $1362 \mathrm{Wm}^{-2}$ in 2013 (Kopp and Lean, 2011; Meftah et al., 2014). Indeed, the CMIP6 pre-industrial simulation (piControl) uses a value of $1361 \mathrm{Wm}^{-2}$ (Matthes et al., 2017). We therefore examine the impact of TSI choice within the context of both pre-industrial and Pliocene climates within Sect. 4.3.2. Recognising this source of uncertainty and the impact on climate anomalies (due to non-linear climate responses) is important, as the PlioMIP2 specification (Haywood et al., 2016, Sect. 2.3.1) leaves the choice of TSI to individual modelling groups, whose TSI may depend upon whether or not the group is a participant of CMIP6. The impact of TSI choice is minimised by the Pliocene community's use of climatological anomalies but should be considered when comparing model-model absolute indices (summer sea ice extent, AMOC strength, etc.).

The land surface scheme is MOSES 2.1 (Met Office Surface Exchange Scheme; Cox et al., 1999; Essery et al., 2003) which principally deals with the hydrology of the canopy to the subsurface and the surface energy balance (including subsurface thermodynamics). Within the scheme there are five plant functional types (PFTs: broadleaf and needleleaf trees, $\mathrm{C}_{3}$ and $\mathrm{C}_{4}$ grasses, and shrub) as well as soil (desert), lakes and ice. Each non-glaciated terrestrial grid cell can take fractional values of each surface type.

The HadCM3 PlioMIP1 study of Bragg et al. (2012) used an earlier version of MOSES (MOSES1) which treats each model grid cell as a homogeneous surface and uses effective parameters to calculate the grid cell's energy and moisture flux. However, MOSES2 introduced subgrid (tiled) heterogeneity and improved representation of surface and plant processes such that hydrological partitioning and energy balance are computed for each subgrid tile. A comparison of MOSES1 and MOSES2.1 can be found within Valdes et al. (2017). In this study, we incorporate a software update taken from the HadGEM2 climate model (Good et al., 2013) which corrects the temperature control of plant respiration (making the model MOSES2.1a in the nomenclature of Valdes et al., 2017).

Runoff is collected in drainage basins and delivered to associated coastal outflow points (on a $3.75^{\circ} \times 2.5^{\circ}$ geographic grid). River transport is not modelled explicitly; instead, runoff is returned to the coastal outflow point in the uppermost ocean layer instantaneously at the atmosphereocean coupling step (Gordon et al., 2000). Internal drainage basins are present but the associated water loss is not explicitly modelled within the routing scheme. Instead, the loss of freshwater in the hydrological cycle is corrected using an artificial freshwater correction field applied to the uppermost surface of the ocean (Sect. 2.2). This freshwater closure also acts to correct the freshwater loss due to terrestrial snowfall accumulation.

\subsection{Ocean and sea ice models}

The ocean component is a rigid-lid model of the Bryan-Cox lineage (Bryan, 1969; Cox, 1984). In the vertical, there are 20 unevenly spaced levels, concentrated near the surface in order to improve representation of the surface mixed layer. The model uses $z$-coordinate vertical layers with bottom topography represented by "full" cells. This leads to a discontinuous representation of the bathymetry which has poorer fidelity at greater depths (where the thickness of levels is greatest). The ocean time step is $1 \mathrm{~h}$, horizontal spatial resolution is $1.25^{\circ} \times 1.25^{\circ}$, and the grid is aligned so that there are six ocean grid cells to each atmosphere grid cell $\left(3.75^{\circ} \times 2.5^{\circ}\right)$. To simplify coupling with the atmosphere model, the ocean model's coastline has a resolution of $3.75^{\circ} \times 2.5^{\circ}$ at the uppermost level.

Within the modern boundary conditions, cells overlying important subgrid-scale channels, such as those along the Denmark Strait, the Iceland-Faroe and the Faroe-Shetland channels, and straits surrounding the Indonesian archipelago, are artificially deepened. Additionally, within the GreenlandIceland-Scotland region, a convective adjustment scheme (Roether et al., 1994) is used to better represent downslope mixing that improves the representation of dense outflows that form the North Atlantic Deep Water (NADW). The scheme is not used for Antarctic Bottom Water (AABW). Water mass exchange through the Strait of Gibraltar, a channel that falls on the subgrid scale, is achieved with a diffusive pipe. This pipe provides transport of water properties through the 13 topmost layers of the ocean $(\sim 1200 \mathrm{~m})$ between the eastern Atlantic and the western Mediterranean. Other subgrid-scale channels, such as the Canadian Archipelago, Hudson Strait outflow and the Makassar Strait, remain spatially unresolved and therefore unrepresented. The latter has been shown to possess most of the Indonesian throughflow (Gordon and Fine, 1996) and so is compensated for within the model by a deepening of regional model bathymetry.

The freshwater budget of the ocean is balanced by fluxes from the river routing scheme and a freshwater correction applied to the uppermost ocean level. Within the preindustrial (and associated $\mathrm{CO}_{2}$ sensitivity experiments), the freshwater correction field is prescribed (time invariant). The correction field had been derived to provide closure of the model's modern hydrological cycle and consists of a uniform background component $\left(0.01 \mathrm{~mm} \mathrm{~d}^{-1}\right)$ correcting internal drainage (Sect. 2.1) and an iceberg component $\left(0.02 \mathrm{~mm} \mathrm{~d}^{-1}\right)$ whose geographic distribution is derived from modern observations (Gordon et al., 2000; Pardaens et al., 2003). Within the Pliocene experiments, we omit the timeinvariant correction (including the iceberg component) and instead use an annual model-derived geographically invariant freshwater correction to reduce residual salinity drifts 
to zero. We justify this as we currently do not have a priori knowledge of the geographic distribution of iceberg melt consistent with the ice sheet distribution within the PlioMIP2 enhanced boundary conditions. In the Northern Hemisphere, we do not expect significant iceberg calving given the configuration of the Greenland Ice Sheet and the lack of marine terminating margins specified within the PRISM4 boundary conditions.

The rigid-lid streamfunction scheme imposes the need for bathymetry to be smoothed particularly in steep regions of the high latitudes and for islands to be specified as line integrals for the barotropic streamfunction. A major consequence of the latter is that the modern Bering Strait throughflow is not fully resolved as it sits between two modeldefined continents between which the barotropic component of flow is poorly resolved. This impacts our interpretation of the Pliocene experiments (closed Bering Strait) with respect to the pre-industrial (open Bering Strait); this is discussed within Sect. 3.2.2. An advantage of the rigid-lid scheme on the other hand is that barotropic gravity waves are neglected, which facilitates the use of longer time steps.

The sea ice model is a simple thermodynamic scheme based upon Semtner (1976) with parameterisations for ice drift and concentration. To account for sea ice leads, upper boundaries of 0.995 and 0.980 are imposed on Arctic and Antarctic sea ice concentrations based upon the parameterisation of Hibler (1979). Ocean salinity is influenced by sea ice formation and melt by assuming a sea ice salinity of $0.6 \mathrm{psu}$ (excess salt, in effect, is returned to the ocean). Sublimation is represented and acts to increase ocean salinity (salt blown into leads), whilst ocean-bound snowfall and precipitation reduce salinity. The effects of snow age and melt pond formation on surface albedo are represented with a linear parameterisation based upon surface temperature. Ice drifts only by the action of surface ocean current; hence, within the model surface, wind stress indirectly influences sea ice drift via its influence on the surface ocean current. Sea ice dynamics is represented by parameterisations based upon Bryan et al. (1975). Ice rheology is simply represented by preventing ice convergence above $4 \mathrm{~m}$ thickness. There is no representation for the interaction between floes.

\section{Experiment design}

Here, we describe the setup of the Pliocene and the preindustrial experiments. The Pliocene experiments have $\mathrm{CO}_{2}$ set to $280,350,400$ and $450 \mathrm{ppm}$, each conducted with modern orbit as specified by the PlioMIP2 protocol (Haywood et al., 2016). These experiments are labelled the control Pliocene experiment Eoi ${ }^{400}$ (PlioMIP2 CORE), Eoi ${ }^{350,450}$ (tier 1; P4F+P4P) and $\mathrm{Eoi}^{280}$ (tier 2; P4F). Here, we use a comma-separated list in the superscript to indicate 2 or more experiments. In all cases, the superscript indicates $\mathrm{CO}_{2}$ (in $\mathrm{ppm}$ ) and the $\mathrm{o}$ and $\mathrm{i}$ indicate the inclusion of the PRISM4 orography (including PRISM4 vegetation, soil and lakes) and ice sheets. The experiments based upon the pre-industrial geography are run with $\mathrm{CO}_{2}$ values of 280,400 and $560 \mathrm{ppm}$. These are identified as the control pre-industrial experiment $\mathrm{E}^{280}$ (CORE), $\mathrm{E}^{400}$ (tier 2; P4F) and $\mathrm{E}^{560}$ (tier 1; P4F).

We also explore two sets of non-protocol experiments to assess sensitivities to Pliocene orbital configuration and the TSI. The PlioMIP2 protocol (Haywood et al., 2016) specifies a modern orbital configuration for all Pliocene experiments. We investigate the validity of this orbit choice by rerunning Eoi $^{400}$ with a $3.205 \mathrm{Ma}$ orbital configuration representing the mid-Piacenzian warm period (mPWP) time slice of Haywood et al. (2013a) within experiment orb $\operatorname{Eoi}^{400}$. We also investigate the choice of total solar irradiance (Sect. 2.1) by rerunning the two control (CORE) experiments with a TSI of $1361 \mathrm{Wm}^{-2}$ within ${ }_{1361} \mathrm{E}^{280}$ and ${ }_{1361}$ Eoi $^{400}$.

In total, six Pliocene experiments were run: the CORE $\left(\operatorname{Eoi}^{400}\right)$, two tier $1\left(\operatorname{Eoi}^{350}\right.$ and $\left.\operatorname{Eoi}^{450}\right)$, one tier $2\left(\operatorname{Eoi}^{280}\right)$, as well as an orbital (orb $\mathrm{Eoi}^{400}$ ) and TSI sensitivity experiment $\left({ }_{1361} \mathrm{Eoi}^{400}\right)$. These are accompanied by four pre-industrialbased experiments: the CORE $\left(\mathrm{E}^{280}\right)$, a tier $1\left(\mathrm{E}^{560}\right)$ and tier $2\left(E^{400}\right)$, as well as a TSI sensitivity experiment $\left({ }_{1361} E^{280}\right)$. These 10 simulations are detailed within Table 1.

\subsection{Pre-industrial and associated sensitivity experiments $\left(E^{280,400,560}\right.$ and $\left.{ }_{1361} E^{280}\right)$}

The experiments with pre-industrial geography are 500-year continuations of a long integration (> 2000 model years) pre-industrial experiment that had been initialised from the observed ocean state of Levitus and Boyer (1994). The experiment uses a topography and a bathymetry regridded and smoothed from ETOPO5 (National Geophysical Data Center, 1993), and vegetation and soil translated from the land cover of Wilson and Henderson-Sellers (1985). Within all experiments, the vegetation scheme is time invariant (fixed). River routing is derived by aggregating runoff in all terrestrial grid boxes within each runoff basin in a manner which is internally consistent with the model topography. All model boundary conditions were developed by the Met Office Hadley Centre (hereafter MOHC) and used within CMIP3/5. In accordance with the PlioMIP2 protocol (Haywood et al., 2016), levels of atmospheric $\mathrm{CO}_{2}$ are set to 280 , 400 and $560 \mathrm{ppm}$, giving the pre-industrial $\left(\mathrm{E}^{280}\right)$ and two $\mathrm{CO}_{2}$ sensitivity experiments $\left(\mathrm{E}^{400}\right.$ and $\left.\mathrm{E}^{560}\right)$. A fourth preindustrial-based experiment, ${ }_{1361} \mathrm{E}^{280}$, is run to investigate the model sensitivity to the choice in TSI value (Sects. 2.1 and 4.3.2). 


\subsection{Pliocene (PlioMIP2 enhanced) and sensitivity experiments (Eoi $280,350,400,450$, orb Eoj ${ }^{400}$ and ${ }_{1361} \mathrm{Eoi}^{400}$ )}

\subsubsection{Boundary condition preparation}

For PlioMIP2, the boundary conditions for the modern-day and the "enhanced" variant of the Pliocene reconstruction are provided on regular $1^{\circ}$ grids held within NetCDF files (USGS, 2016; Haywood et al., 2016). For convenience, we shall refer to the PlioMIP2 enhanced boundary condition as PRISM4. The modern geography is provided to facilitate the anomaly method of boundary condition generation. The LSM is created by computing the anomaly of PRISM4 Pliocene minus PRISM4 modern (at $1^{\circ}$ resolution) and regridding using bilinear interpolating to the $3.75^{\circ} \times 2.5^{\circ}$ model grid and then applying the anomaly to the model's pre-industrial LSM. This is so that the final reconstruction is consistent with both the original pre-industrial model setup and the PRISM4 LSM. Finally, a number of manual corrections were applied to the resulting $3.75^{\circ} \times 2.5^{\circ}$ PRISM4 LSM to ensure that the underlying character of the PRISM4 reconstruction is represented as best as reasonably practicable at the model's resolution. For consistency with the preindustrial boundary conditions developed by $\mathrm{MOHC}$, we remove Svalbard and Novaya Zemlya, despite their subaerial extension within PRISM4. Similarly, we keep the Pliocene LSM in the Persian Gulf region the same as pre-industrial despite a withdrawal of the Persian Gulf within PRISM4. This choice was made as the Persian Gulf within the pre-industrial LSM is represented by an inland sea (due to inadequate spatial resolution) and so further changes would be difficult to interpret. At model resolution, the Pliocene Strait of Gibraltar is identical to the pre-industrial and so the diffusive pipe is incorporated.

The resulting PRISM4 LSM was used to constrain the generation of the Pliocene orography and bathymetry (which was generated using area-weighted regridding and then applied as an anomaly to the existing HadCM3 pre-industrial orography and bathymetry). River basins and outflow points were derived from the pre-industrial routing scheme (Sect. 3.1) but corrected in regions of LSM, topographical and ice-bedrock change using a model-resolution river routing model based on the D8 method (Tribe, 1992). This was then followed by manual correction in regions where model resolution fails to capture important orography, or where the regridded Pliocene orography is flat. The PRISM4 vegetation scheme (represented by BIOME4 biomes) was regridded by combining a BIOME4-to-MOSES2 lookup table with an area-weighted survey of underlying biomes. The vegetation scheme is then held fixed within each experiment. A similar area-weighted regridding was conducted for the lake field. We chose not to generate the lake field as an anomaly from the modern lake distribution, as land surface change since the
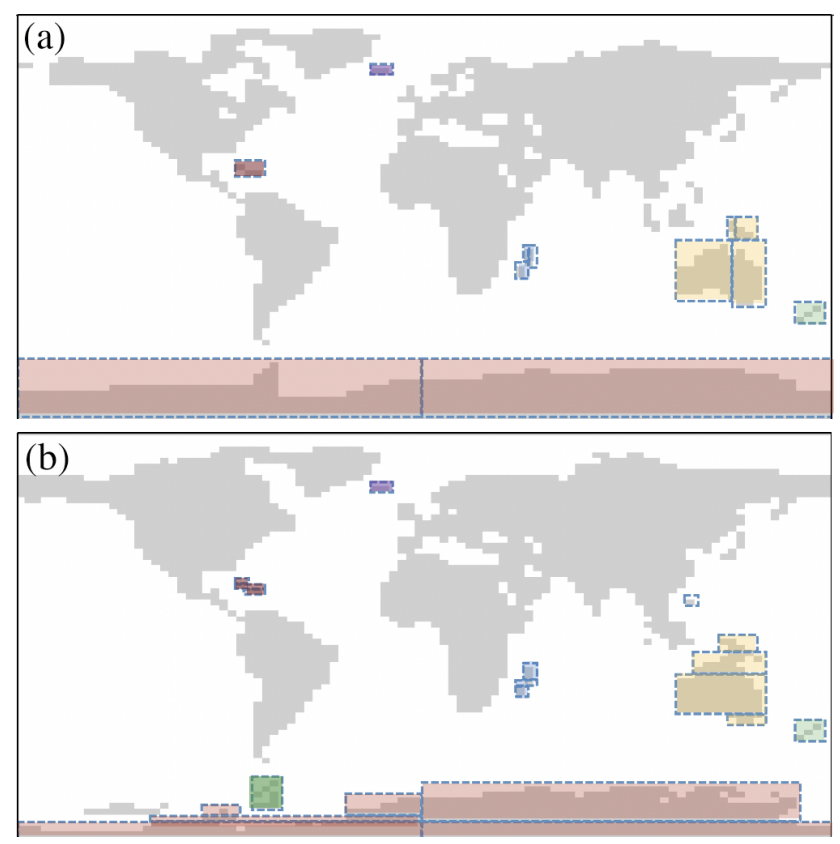

Figure 1. LSM and barotropic streamfunction island configuration for the (a) pre-industrial and (b) Pliocene.

pre-industrial would be imprinted on the model's lake distribution.

\subsubsection{Barotropic streamfunction island configuration}

Rigid-lid Bryan-Cox-type models, such as the ocean of HadCM3, require islands (and by extension, continents) to be identified so that a net non-zero barotropic flow (depth independent) can be achieved around the line integral (streamfunction non-zero). The default pre-industrial configuration of the model has six islands defined and is shown within Fig. 1. For consistency, aforementioned (Sect. 3.2.1) manual corrections to both LSM and bathymetry have allowed islands to be specified that are consistent with the $\mathrm{E}^{280}$ experiment but also reflect the key palaeogeographic changes presented by the PRISM4 palaeogeography. In particular, western Iceland and East Greenland land cells were adjusted to ensure that Iceland could be defined as a streamfunction island (Fig. 1), and hence we could fully represent the East Greenland Current. The island to the west of the Antarctic Peninsula body lies outside the island definition of the main Antarctic continent and therefore the circulation between the two is not fully resolved (only the baroclinic flow is resolved fully). Figure 1 compares the pre-industrial and PRISM4 Pliocene HadCM3 island specification. It can be seen that the six islands in the pre-industrial configuration have been increased to eight islands in the Pliocene.

It is noted that within the pre-industrial HadCM3 model setup the Bering Strait barotropic component of throughflow is unresolved and both the Makassar Strait and the 
Canadian Archipelago are spatially unresolved (Sect. 2.2). This poses a conceptual problem in the interpretation of the Pliocene experiments with respect to the pre-industrial, as the PRISM4 Pliocene geography has these throughflow regions closed. Therefore, our simulations do not resolve the full climatic response of these regional palaeogeographic changes. A pre-industrial experiment with a fully resolved Bering Strait and Canadian Archipelago would partially address these problems but would then force a divergence away from the previous HadCM3 descriptions and evaluations, as well as from past and current CMIP/PMIP and PlioMIP1 model implementations. These problems are likely to arise in all rigid-lid streamfunction ocean models that have insufficient spatial resolution to fully resolve these gateways and inherently cannot resolve line integrals around bounding land masses. Ocean models that have explicit or implicit free-surface schemes with sufficiently high horizontal spatial resolution may reduce these issues.

\subsection{Pliocene model initialisation and spin-up}

Model spin-up is conducted in a series of stages in which the model and boundary conditions are increased in complexity. These stages are as follows:

1. The atmosphere model (AGCM) was initialised in a 50-year run with PRISM4 LSM, basic surface scheme (lakes, ice, shrubs and orography), pre-industrial $\mathrm{CO}_{2}$ (280 ppm), as well as zonal hemispheric-symmetric monthly sea surface temperature (SST) and sea ice distribution derived from the initial 2500 model year preindustrial HadCM3 simulation from Sect. 3.1. Model failures at this stage allow for the identification of steep topography that requires regional smoothing.

2. The ocean model is added (without barotropic physics) and the resulting AOGCM run is continued for 100 years with Pliocene bathymetry and river scheme (year 50 within Fig. 2).

3. Barotropic physics is incorporated (without specifying islands) and the simulation is continued for 200 years. Regional bathymetric smoothing was applied in regions which caused model failure (Fig. 2 stage a).

4. The island configuration (Sect. 3.2.2, Fig. 1) is then derived using an iterative series of sensitivity tests in which each island configuration is refined. Once complete, the set of island line integrals is incorporated into the model configuration. At this stage, we have an AOGCM incorporating full barotropic physics (Fig. 2 stage $b$ ).

5. $\mathrm{CO}_{2}$ is increased from $280 \mathrm{ppm}$ at $1 \% \mathrm{yr}^{-1}$ until $400 \mathrm{ppm}$ is attained. $\mathrm{CO}_{2}$ is then held fixed.

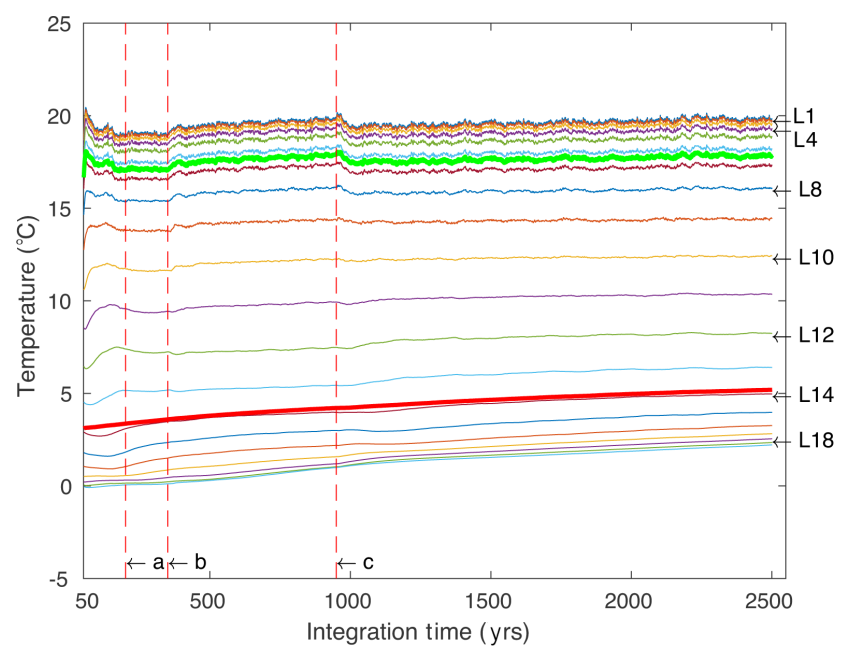

Figure 2. Time evolution of the globally integrated temperature for the ocean layers within the Eoi ${ }^{400}$ experiment. Whole ocean volume is indicated by the thick red line and the top $200 \mathrm{~m}$ are indicated by the thick green line. Vertical lines indicate key spin-up stages: (a) adding the barotropic physics to the ocean model, (b) incorporation of barotropic streamfunction islands into the barotropic solver and (c) correction to the barotropic streamfunction island in the southern high latitudes and incorporation of full PRISM4 vegetation boundary conditions into the model. The midpoints to the ocean layers are $5 \mathrm{~m}$ (L1), $15 \mathrm{~m}$ (L2), $15 \mathrm{~m}$ (L3), $35 \mathrm{~m}$ (L4), $48 \mathrm{~m}$ (L5), 67 m (L6), 96 m (L7), 139 m (L8), 204 m (L9), 301 m (L10), $447 \mathrm{~m}$ (L11), $666 \mathrm{~m}$ (L12), $996 \mathrm{~m}$ (L13), $1501 \mathrm{~m}$ (L14), $2116 \mathrm{~m}$ (L15), 2731 m (L16), 3347 m (L17), 3962 m (L18), 4577 m (L19) and $5195 \mathrm{~m}$ (L20).

6. At model year 950, a problem with ancillary file generation had been resolved allowing the vegetation boundary condition to be incorporated into the model. Additionally, a regional modification was made to the bathymetry and streamfunction island configuration to the west of the Antarctic Peninsula to resolve a persistent numerical mode within the barotropic solver in this region (Fig. 2 stage c). The final island configuration is shown within Fig. 1.

7. The AOGCM model was then set to continue to the year 2000.

8. At the year 2000, five additional experiments are spun off that run alongside $\mathrm{Eoi}^{400}$ (Table 1). These are Eoi $^{280,350,450}$, orb Eoi ${ }^{400}$ and ${ }_{1361}$ Eoi $^{400}$. All six experiments are run to the year 2400 .

9. The models are then run for the final 100 years configured with full climatological output.

\subsection{Equilibrium state}

By model years 2400 to 2500 , the Pliocene control experiment $\left(\operatorname{Eoi}^{400}\right)$ has achieved a quasi-steady-state equi- 
Table 2. Summary of equilibrium state metrics for the seven PlioMIP2 protocol experiments. Globally integrated $\left(\right.$ Ocean $\left._{\mathrm{all}}\right)$ and

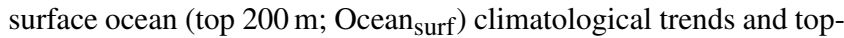
of-the-atmosphere energy balance $\left(\mathrm{TOA}_{\mathrm{EB}}\right)$ are derived from the last 100 model years.

\begin{tabular}{|c|c|c|c|}
\hline ID & $\begin{array}{r}\text { Ocean }_{\text {all }} \\
\left({ }^{\circ} \mathrm{C} \text { century }^{-1}\right)\end{array}$ & $\begin{array}{r}\text { Ocean }_{\text {surf }} \\
\left({ }^{\circ} \text { century }^{-1}\right)\end{array}$ & $\begin{array}{r}\text { TOAEB }_{E B} \\
\left(\mathrm{Wm}^{-2}\right)\end{array}$ \\
\hline Eoi $^{450}$ & 0.063 & 0.046 & 0.260 \\
\hline Eoi $^{400}$ & 0.041 & -0.026 & 0.047 \\
\hline Eoi $^{350}$ & 0.017 & 0.002 & -0.024 \\
\hline Eoi $^{280}$ & 0.017 & 0.002 & -0.090 \\
\hline$E^{280}$ & -0.014 & 0.008 & -0.115 \\
\hline$E^{400}$ & -0.048 & 0.010 & 0.098 \\
\hline$E^{560}$ & 0.107 & 0.025 & 0.334 \\
\hline
\end{tabular}

librium in which the globally integrated net top-of-theatmosphere (TOA) radiative imbalance is $0.047 \mathrm{Wm}^{-2}$, surface $(1.5 \mathrm{~m})$ air temperature trend is $0.08^{\circ} \mathrm{C}_{\text {century }}{ }^{-1}$ and ocean potential temperature trends within the upper $200 \mathrm{~m}$ and globally integrated are -0.026 and $0.041^{\circ} \mathrm{C}_{\text {century }}{ }^{-1}$. The corresponding values for the pre-industrial control experiment $\left(\mathrm{E}^{280}\right)$ are $-0.115 \mathrm{Wm}^{-2}, 0.052,0.008$ and $-0.014^{\circ} \mathrm{C}$ century ${ }^{-1}$, respectively. High- $\mathrm{CO}_{2}$ experiments, $\mathrm{Eoi}^{450}$ and $\mathrm{E}^{560}$ present the largest, yet modest, departures from equilibrium and are characterised by TOA imbalance $>0.2 \mathrm{Wm}^{-2}$. Positive TOA imbalance is indicative of a warming of the Earth system, the small heat capacity of the atmosphere means that residual energy is predominantly taken up by the ocean, which is reflected in the volumeintegrated ocean temperature evolution. Warming of the deep ocean is primarily occurring at depths deeper than $2000 \mathrm{~m}$ in the Pacific basin. The Indian and Antarctic oceans are the most equilibrated, particularly at intermediate depths and deeper. Table 2 summarises the equilibrium states of the seven PlioMIP2 experiments and Fig. 2 presents the time evolution of ocean potential temperature of the Pliocene control experiment $\left(\mathrm{Eoi}^{400}\right)$. All experiments are deemed to be in a satisfactory state of equilibrium, although the high TOA imbalance simulations $\operatorname{Eo}^{450}$ and $\mathrm{E}^{560}$ have above-average warming within the deep ocean.

\section{Results}

We base our analysis on climatological averages from the final 50 years of each simulation. The final 50 years of output are used to remain consistent with the HadCM3 PlioMIP1 submission (Exp. 2 of Bragg et al., 2012). The PlioMIP2 protocol (Haywood et al., 2016) does not state a standardised time length for climatological means although the PlioMIP2 website (USGS, 2018) does request 100 years of monthly climatology. We therefore make the 50-year climatological average and 100 years of monthly climatology available on the PlioMIP2 data repository.

In order to keep discussion clear and concise, we principally compare the two PlioMIP2 CORE experiments, which we refer to as the control experiments (Eoi ${ }^{400}$ and $E^{280}$ ). Whilst there is uncertainty in mid-Piacenzian (MIS KM5c) $\mathrm{CO}_{2}$ levels, $400 \mathrm{ppm}$ represents the middle of the anticipated $\mathrm{CO}_{2}$ range derived from marine- and terrestrial-based reconstructions (Haywood et al., 2016, and references therein). We therefore consider Eoi $^{400}$ as our "best estimate" simulation. In addition, when referring to climate forcing, we use the term "palaeogeography" to encompass the combined change in topography, land surface (vegetation, lakes, soils, ice sheets), LSM and bathymetry which we diagnose from the anomaly $\mathrm{Eoi}^{280}$ minus $\mathrm{E}^{280}$.

\subsection{State of the atmosphere and Earth surface climatology}

\subsubsection{Surface air temperature and climate sensitivity}

Modelled mean annual $1.5 \mathrm{~m}$ surface air temperatures (hereafter MASAT) are detailed within Table 3 and corresponding Pliocene anomalies are shown within Fig. 3. Relative to the pre-industrial control $\left(\mathrm{E}^{280}\right)$ temperatures are generally warmer within the Pliocene experiments. Very high differences in MASAT of up to $31.3^{\circ} \mathrm{C}$ are reached over regions of Greenland and Antarctica, where the elevation of Pliocene ice sheets has been changed with respect to the present. Typically, warming is greatest over land, although in ocean regions at or near Antarctic LSM change (preindustrial grounded ice to Pliocene ocean) warming is significant. This pattern of warming is similar to results derived with HadCM3 within PlioMIP1 under PRISM3 boundary conditions (Exp. 2 of Bragg et al., 2012).

The Pliocene cooling in the Barents Sea is statistically significant and persistent through the model integration (Fig. 3). It coincides with an increase in Pliocene winter and spring sea ice concentration driven by palaeogeographic terrestrial winter cooling in the circum-Arctic (Pliocene subaerial Barents and Baltic Sea). This cooling is potentially driven by the partial suppression of northward heat transport (in the Norwegian Current) by the subaerial extension of Ireland and Scotland within the model.

The Eoi ${ }^{400}-\mathrm{E}^{280}$ MASAT anomaly of $2.9^{\circ} \mathrm{C}$ (Table 3) is lower than the $3.3^{\circ} \mathrm{C}$ of HadCM3 within PlioMIP1 (Bragg et al., 2012) and lies within the PlioMIP1 model ensemble range of $1.84-3.60^{\circ} \mathrm{C}$ (Haywood et al., 2013b). The MASAT anomaly also lies between the PlioMIP2 studies of Kamae et al. (2016) $\left(2.4^{\circ} \mathrm{C}\right)$ and Chandan and Peltier (2017) $\left(3.8^{\circ} \mathrm{C}\right)$, although note that this comparison is not exhaustive as PlioMIP2 is incomplete at the time of press. Table 3 also presents MASAT data for the equatorial (between $30^{\circ} \mathrm{S}$ and $30^{\circ} \mathrm{N}$ ) and polar regions (latitudes greater than $60^{\circ}$ ). The resulting polar amplification factors for the Pliocene control 
Table 3. Global mean annual surface air temperature (MASAT) and the mean annual surface air temperatures of the polar (poleward of $60^{\circ}$ ) and tropical (equatorward of $30^{\circ}$ ) regions. The polar amplification factor is shown in square brackets and is defined as the ratio in the anomalies (against $\mathrm{E}^{280}$ ) between the polar warming and the global mean warming.

\begin{tabular}{lrrrrr}
\hline ID & MASAT $\left({ }^{\circ} \mathrm{C}\right)$ & $\Delta T$ against $\mathrm{E}^{280}$ & NH polar MASAT $\left({ }^{\circ} \mathrm{C}\right)$ & Tropical MASAT $\left({ }^{\circ} \mathrm{C}\right)$ & SH polar MASAT $\left({ }^{\circ} \mathrm{C}\right)$ \\
\hline $\mathrm{Eoi}^{450}$ & $17.4 \pm 0.1$ & +3.4 & $-4.6 \pm 0.4[1.6]$ & $27.6 \pm 0.1$ & $-10.5 \pm 0.4[2.1]$ \\
$\mathrm{Eoi}^{400}$ & $16.9 \pm 0.1$ & +2.9 & $-5.2 \pm 0.3[1.7]$ & $27.2 \pm 0.1$ & $-11.2 \pm 0.3[2.2]$ \\
$\mathrm{orb}^{\mathrm{Eoi}} 400$ & $16.8 \pm 0.1$ & +2.8 & $-5.2 \pm 0.4[1.7]$ & $27.1 \pm 0.1$ & $-11.4 \pm 0.3[2.2]$ \\
$\mathrm{Eoi}^{350}$ & $16.3 \pm 0.1$ & +2.3 & $-6.2 \pm 0.3[1.7]$ & $26.7 \pm 0.2$ & $-11.8 \pm 0.4[2.5]$ \\
$\mathrm{Eoi}^{280}$ & $15.4 \pm 0.1$ & +1.4 & $-8.1 \pm 0.4[1.4]$ & $25.9 \pm 0.1$ & $-12.6 \pm 0.3[3.5]$ \\
$\mathrm{E}^{280}$ & $14.0 \pm 0.1$ & 0 & $-10.0 \pm 0.3$ & $25.1 \pm 0.2$ & $-17.5 \pm 0.3$ \\
$\mathrm{E}^{400}$ & $15.8 \pm 0.1$ & +1.8 & $-6.8 \pm 0.3[1.8]$ & $26.5 \pm 0.2$ & $-15.5 \pm 0.4[1.1]$ \\
$\mathrm{E}^{560}$ & $17.5 \pm 0.1$ & +3.5 & $-3.8 \pm 0.3[1.8]$ & $28.0 \pm 0.2$ & $-13.4 \pm 0.4[1.2]$ \\
\hline
\end{tabular}

(a) ANN Eoi ${ }^{450}-E^{280}$

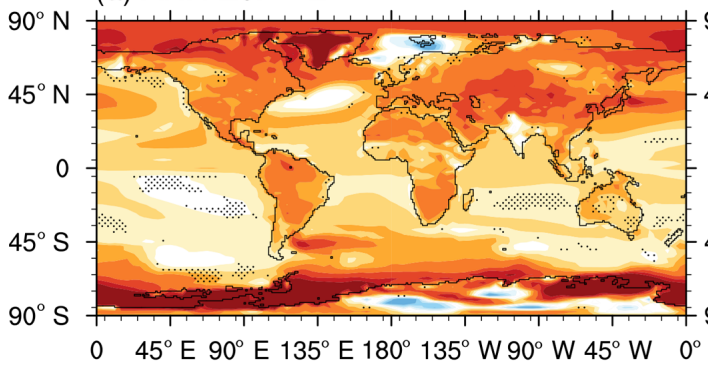

(c) ANN Eoi ${ }^{350}-E^{280}$

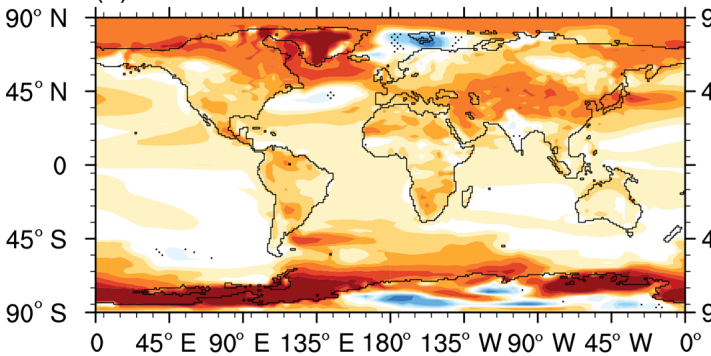

(b) ANN Eoi ${ }^{400}-E^{280}$

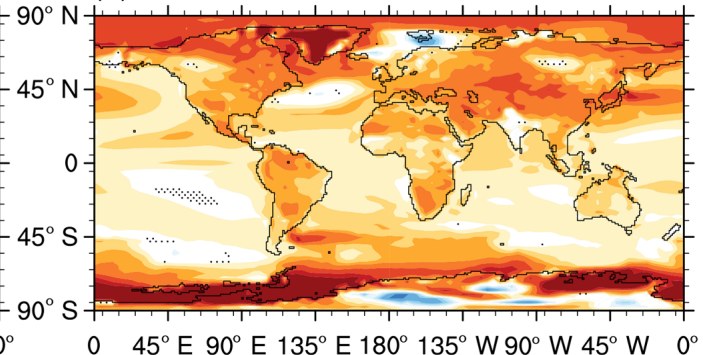

(d) ANN Eoi ${ }^{280}-E^{280}$
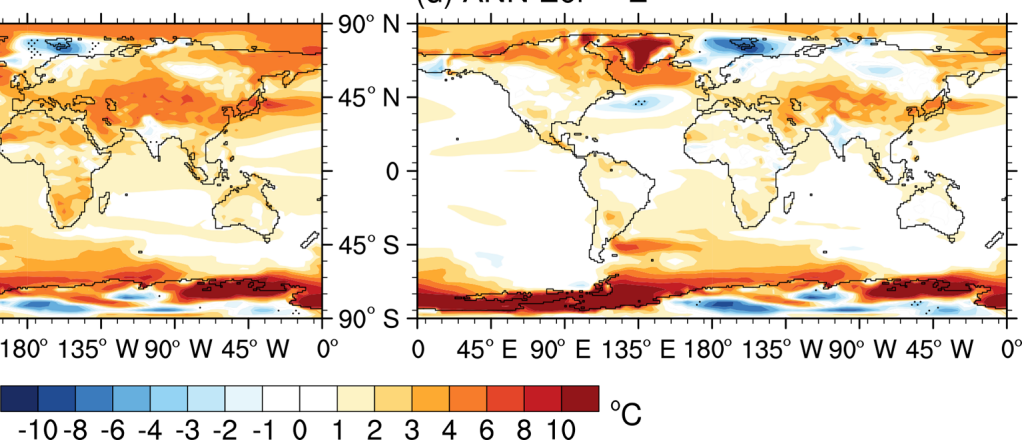

Figure 3. Pliocene annual mean surface air temperature anomalies against $E^{280}$. (a) Eoi ${ }^{450}-E^{280}$, (b) Eoi $^{400}-E^{280}$, (c) Eoi ${ }^{350}-E^{280}$ and (d) $\mathrm{Eoi}^{280}-\mathrm{E}^{280}$. Stippling indicates regions in which results are not statistically significant at a $95 \%$ confidence criterion (independent two-sample Student's $t$ test).

$\left(\right.$ Eoi $\left.^{400}\right)$ relative to the pre-industrial control $\left(\mathrm{E}^{280}\right)$ are 1.7 for the Northern Hemisphere and 2.2 for the Southern Hemisphere.

Figure 4 shows the annual and seasonal temperature anomalies for $\operatorname{Eoi}^{280}$ and $\operatorname{Eoi}^{400}\left(\right.$ against $\mathrm{E}^{280}$ ). Terrestrial regions that are exposed only within the Pliocene, such as the Hudson Bay and the Baltic Sea regions, are up to $10^{\circ} \mathrm{C}$ warmer (colder) during the summer (winter) seasons, due to land-ocean heat capacity contrast. It is unclear how much of this seasonal temperature response in the Baltic Sea region (exposed during the Pliocene) is a driver of persistent cooling within the Barents Sea region.
From the results in Table 3, it is possible to diagnose the factors that contribute to Pliocene warming relative to the pre-industrial $\left(\mathrm{E}^{280}\right)$. Considering the Pliocene control experiment $\left(\mathrm{Eoi}^{400}\right)$, we find that the change in palaeogeography $\left(\operatorname{Eoi}^{280}-\mathrm{E}^{280}\right)$ accounts for a temperature change of $1.4^{\circ} \mathrm{C}$, whilst the increase in $\mathrm{CO}_{2}\left(\mathrm{Eoi}^{400}-\mathrm{Eoi}^{280}\right)$ accounts for a further $1.5^{\circ} \mathrm{C}$ of warming. Considering uncertainty in Pliocene $\mathrm{CO}_{2}$ level, we find temperature changes of 0.9 and $2.0^{\circ} \mathrm{C}$ for $\mathrm{Eoi}^{350}-\mathrm{Eoi}^{280}$ and $\mathrm{Eoi}^{450}-\mathrm{Eoi}^{280}$, respectively. The PlioMIP2 experimental design provides a second pathway to examine Pliocene palaeogeographical and $\mathrm{CO}_{2}$ forcing (e.g. $\mathrm{Eoi}^{400}-\mathrm{E}^{400}$ and $\mathrm{E}^{400}-\mathrm{E}^{280}$ ). Within this pathway, the Pliocene geography $\left(\mathrm{Eoi}^{400}-\mathrm{E}^{400}\right)$ accounts for $1.1^{\circ} \mathrm{C}$ of 
(a) ANN Eoi ${ }^{280}-E^{280}$

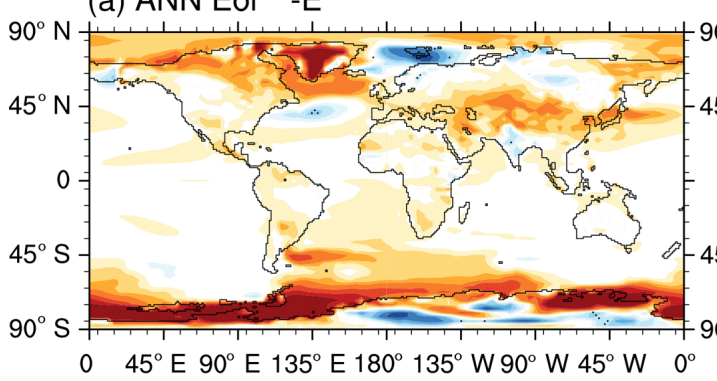

(c) JJA Eoi ${ }^{280}-E^{280}$

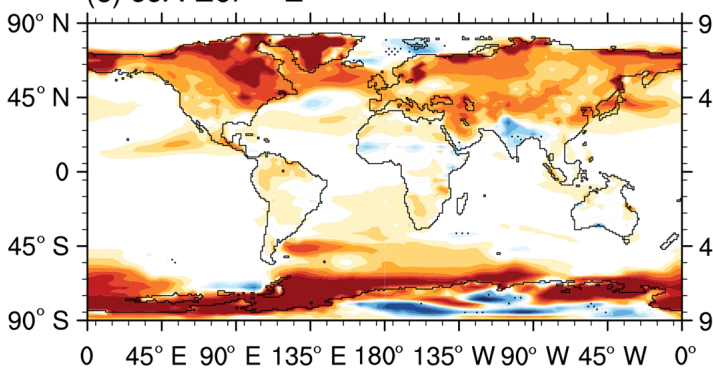

(e) DJF Eoi ${ }^{280}-E^{280}$

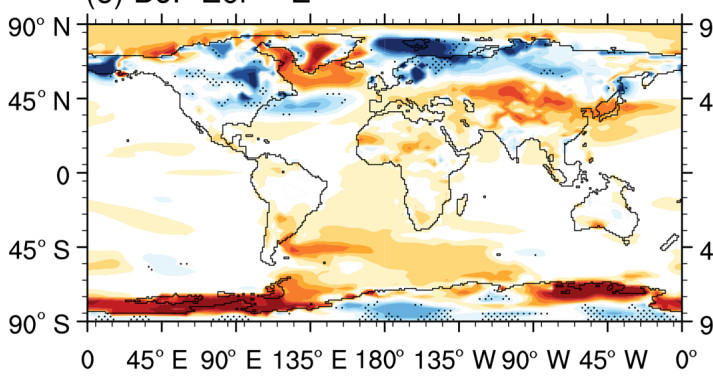

(b) ANN Eoi ${ }^{400}-E^{280}$

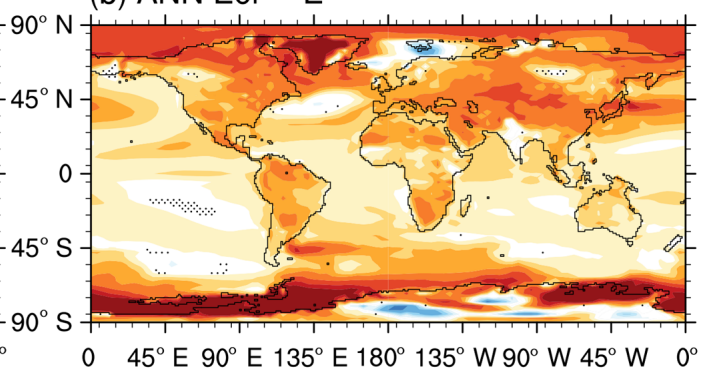

(d) JJA Eoi ${ }^{400}-E^{280}$

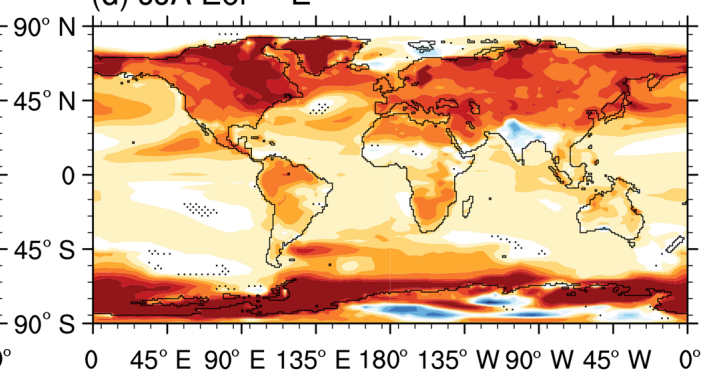

(f) DJF Eoi ${ }^{400}-E^{280}$
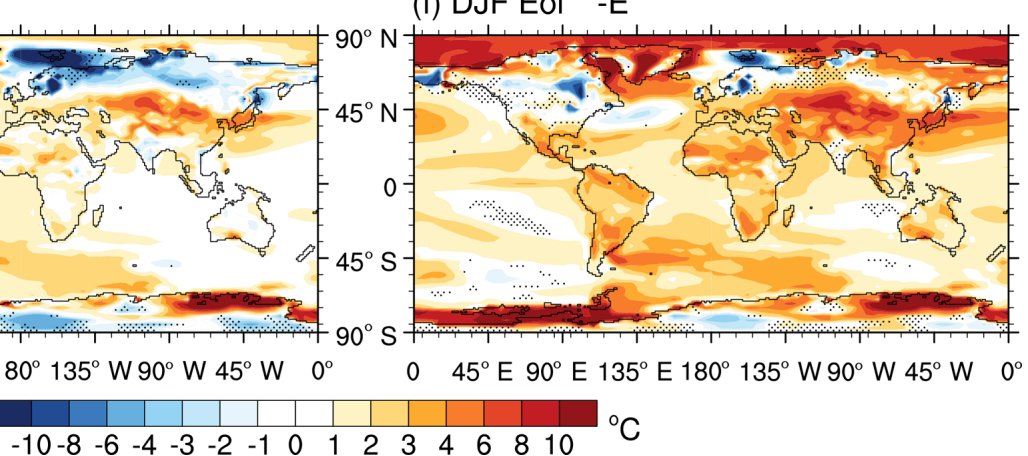

Figure 4. Mean annual and seasonal Pliocene temperature anomalies against $\mathrm{E}^{280}$. (a) Annual Eoi ${ }^{280}-\mathrm{E}^{280}$, (b) annual Eoi ${ }^{400}-\mathrm{E}^{280}$, (c) June-July-August (JJA) Eoi ${ }^{280}-\mathrm{E}^{280}$, (d) JJA Eoi ${ }^{400}-\mathrm{E}^{280}$, (e) December-January-February (DJF) Eoi ${ }^{280}-\mathrm{E}^{280}$ and (f) DJF Eoi $^{400}$ $\mathrm{E}^{280}$. Stippling indicates regions in which results are not statistically significant at a $95 \%$ confidence criterion.

warming and the increase in $\mathrm{CO}_{2}\left(\mathrm{E}^{400}-\mathrm{E}^{280}\right)$ accounts for $1.8^{\circ} \mathrm{C}$ of temperature increase. These differences highlight that there are non-linearities within the climate system's response to changes in boundary condition.

The climate system's sensitivity to a doubling of $\mathrm{CO}_{2}$ (climate sensitivity; CS) is $3.5^{\circ} \mathrm{C}$ for the pre-industrial (derived from $\mathrm{E}^{560}$ and $\mathrm{E}^{280}$ ) and $2.9^{\circ} \mathrm{C}$ for the Pliocene (derived from Eoi ${ }^{400}$ and Eoi $^{280}$ and scaled by 1.94 (= $\log (560 / 280) / \log (400 / 280))$. The pre-industrial CS is consistent with the $3.3^{\circ} \mathrm{C}$ for HadCM3 within CMIP3 (Randall et al., 2007). The Pliocene CS is similar to the $3.1^{\circ} \mathrm{C}$ for $\mathrm{HadCM} 3$ and lies at the lower end of the $2.7-4.1^{\circ} \mathrm{C}$ ensemble range of PlioMIP1 experiment 2 (Haywood et al., 2013b). When we approximate Earth system sensitivity (ESS) using

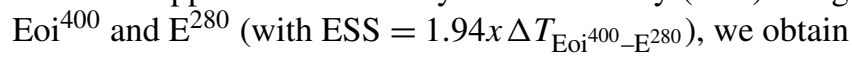
$\sim 5.6^{\circ} \mathrm{C}$. Subsequently the ESS / CS ratio is $\sim 1.9$, which lies at the higher end of the 1.1-2.0 range of the PlioMIP1 ensemble (Haywood et al., 2013b) in which HadCM3 had a ratio of 2.0. It must be noted, however, that such a comparison of CS and ESS is only meaningful when one assumes that the PlioMIP2 enhanced boundary condition approximates the equilibrated Earth system under a contemporary doubling of $\mathrm{CO}_{2}$, which is a reasonable position since the changes in non-glacial elements of the PRISM4 retrodicted palaeogeography are relatively small.

\subsubsection{Precipitation}

The globally integrated mean annual precipitation (MAP; Table 4) is influenced by both Pliocene geography and $\mathrm{CO}_{2}$ changes. Pliocene geography acts to increase globally integrated MAP, although this appears sensitive to the background $\mathrm{CO}_{2}$ level (e.g. Pliocene geography increases MAP by 0.07 and $0.05 \mathrm{~mm} \mathrm{~d}^{-1}$ at 280 and $400 \mathrm{ppm}$, respectively). The $\operatorname{Eoi}^{400}-\mathrm{E}^{280} \mathrm{MAP}$ anomaly of $0.11 \mathrm{~mm} \mathrm{~d}^{-1}$ (Table 4) compares with the $0.17 \mathrm{~mm} \mathrm{~d}^{-1}$ from HadCM3 within 
(a) ANN Eoi ${ }^{450}-E^{280}$

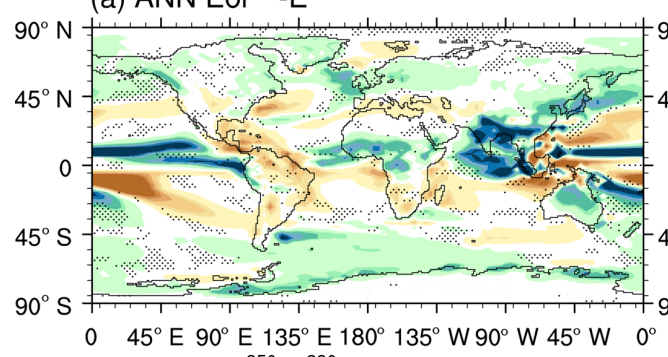
(c) ANN Eoi ${ }^{350}-E^{280}$

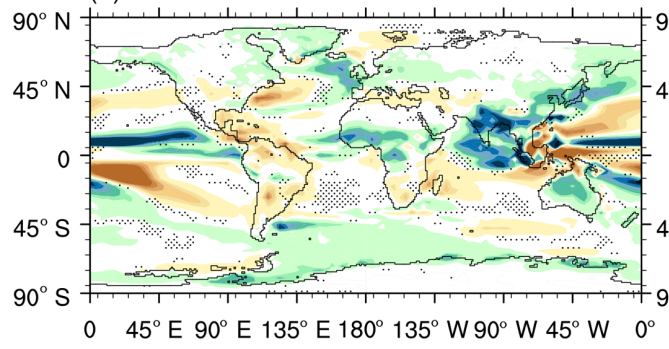

(b) ANN Eoi ${ }^{400}-E^{280}$

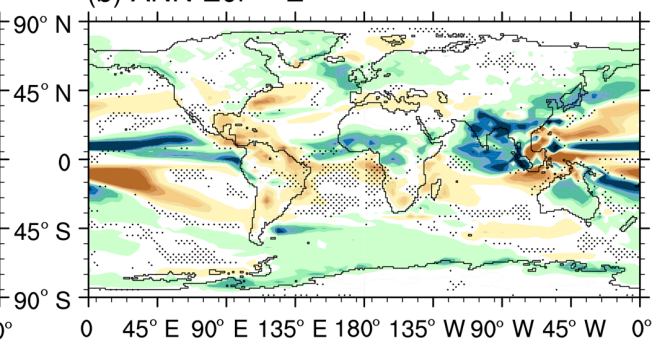

(d) ANN Eoi ${ }^{280}-E^{280}$

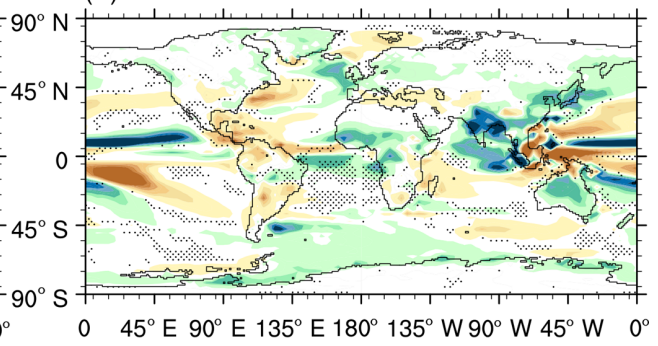

$1.5 \quad 2 \quad 2.5 \mathrm{~mm} \mathrm{~d}^{-1}$

(a) $\mathrm{Eoi}^{450}-\mathrm{E}^{280}$, (b) $\mathrm{Eoi}^{400}-\mathrm{E}^{280}$, (c) $\mathrm{Eoi}^{350}-\mathrm{E}^{280}$ and (d) $\mathrm{Eoi}^{280}$

Figure 5. Pliocene mean annual precipitation anomalies against $\mathrm{E}^{280}$. (a) $\mathrm{Eoi}^{450}-\mathrm{E}^{280}$, (b) $\mathrm{Eoi}^{400}-\mathrm{E}^{280}$, (c)
$\mathrm{E}^{280}$. Stippling indicates regions in which results are not statistically significant at a $95 \%$ confidence criterion.

Table 4. Globally integrated mean annual precipitation (MAP).

\begin{tabular}{lr}
\hline ID & MAP $\left(\mathrm{mm} \mathrm{d}^{-1}\right)$ \\
\hline Eoi $^{450}$ & $3.041 \pm 0.007$ \\
Eoi $^{400}$ & $3.025 \pm 0.008$ \\
orb $^{40 i}$ & \\
Eoi $^{350}$ & $3.027 \pm 0.008$ \\
Eoi $^{280}$ & $3.012 \pm 0.009$ \\
E $^{280}$ & $2.979 \pm 0.008$ \\
E $^{400}$ & $2.912 \pm 0.008$ \\
E $^{560}$ & $2.975 \pm 0.007$ \\
\hline
\end{tabular}

PlioMIP1 (Bragg et al., 2012) and sits at the lower end of the $\sim 0.09-0.18 \mathrm{~mm} \mathrm{~d}^{-1}$ range of the PlioMIP1 model ensemble (Haywood et al., 2013b).

The geographical distribution of MAP change can be seen within Fig. 5. Northern Hemisphere land masses generally see increased precipitation within the Pliocene, although this effect is minimal in the continental interiors. In the Southern Hemisphere, much of South America and south Africa receive less precipitation, whilst Australia and northern Greenland see an increase in precipitation during the Pliocene. Increasing Pliocene $\mathrm{CO}_{2}$ generally intensifies the precipitation anomaly, which is most apparent in the tropics. Regions that receive little precipitation within $\mathrm{E}^{280}$; e.g. north Africa and the East Antarctic Ice Sheet have little $\left(<0.1 \mathrm{~mm} \mathrm{~d}^{-1}\right)$ change in precipitation under increasing Pliocene $\mathrm{CO}_{2}$.

Seasonal plots of precipitation change between the Pliocene $\left(\mathrm{Eoi}^{400}\right)$ and the pre-industrial $\left(\mathrm{E}^{280}\right)$ control ex- periments are shown in Fig. 6. During the Pliocene, we see wetter summers over much of North America and northern Europe. Regions experiencing reduced precipitation in western North America as well as central and western Europe are a consequence of weakened westerlies (not shown). As can be seen within Fig. 6c-f, the Pliocene geography and land surface change drive an intensification of precipitation associated with the Intertropical Convergence Zone (ITCZ), although changes in seasonal latitudinal distribution are not evident. The South Pacific Convergence Zone, extending from the western Pacific warm pool (WPWP) southeastward to the south central Pacific, extends $\sim 15^{\circ}$ further east in $\mathrm{E}^{280}$ than Eoi $^{400}$ and Eoi ${ }^{280}$.

\subsubsection{Planetary-scale atmospheric circulation}

The time-averaged zonal mean meridional mass transport streamfunction for the atmosphere is shown within Fig. 7. Clearly distinguished are the Hadley, the Ferrel and the polar cells. Taking the maximum of the meridional streamfunction as a measure of the Hadley cell strength, we find that the Pliocene geography acts to weaken (intensify) the Hadley cell within the Northern (Southern) Hemisphere. Looking at $\mathrm{E}^{280}$, we find the northern cell is stronger $(+10.8 \%)$ than the southern cell, which is in contradiction with observational and reanalysis data (Stachnik and Schumacher, 2011) that consistently show the southern cell being stronger than the northern cell. With increasing Pliocene $\mathrm{CO}_{2}$, the southern cell intensifies and becomes stronger than the north $(+19 \%$ in $\mathrm{Eoi}^{280}$ and $+42 \%$ in $\mathrm{Eoi}^{400}$ ). This intensification (weakening) of the Hadley cell under changed land surface and ge- 
(a) ANN Eoi ${ }^{280}-E^{280}$

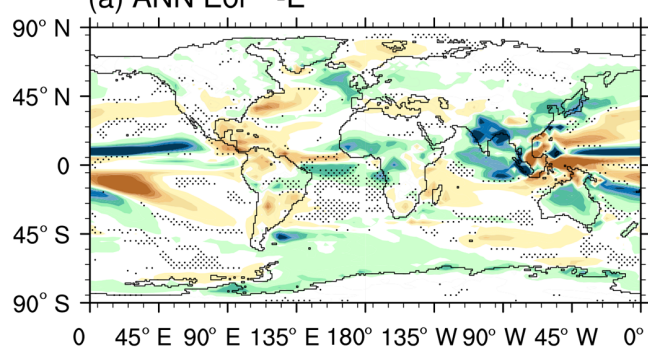

(c) JJA Eoi ${ }^{280}-\mathrm{E}^{280}$

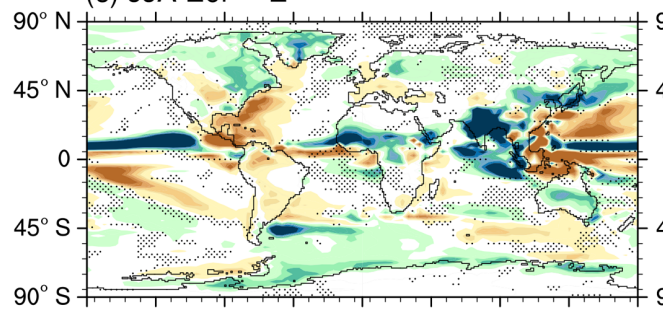

$045^{\circ} \mathrm{E} 90^{\circ} \mathrm{E} 135^{\circ} \mathrm{E} 180^{\circ} 135^{\circ} \mathrm{W} 90^{\circ} \mathrm{W} 45^{\circ} \mathrm{W} \quad 0^{\circ}$ (e) DJF Eoi ${ }^{280}-E^{280}$

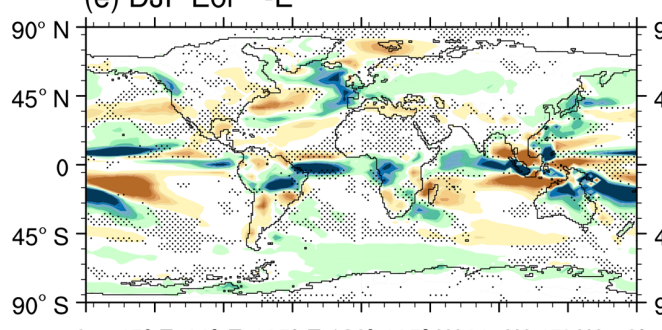

$045^{\circ} \mathrm{E} 90^{\circ} \mathrm{E} 135^{\circ} \mathrm{E} 180^{\circ} 135^{\circ} \mathrm{W} 90^{\circ} \mathrm{W} 45^{\circ} \mathrm{W} \quad 0^{\circ}$ (b) ANN Eoi ${ }^{400}-E^{280}$

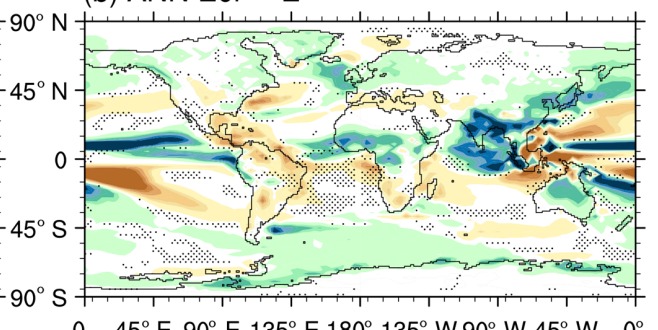

$45^{\circ} \mathrm{E} 90^{\circ} \mathrm{E} 135^{\circ} \mathrm{E} 180^{\circ} 135^{\circ} \mathrm{W} 90^{\circ} \mathrm{W} 45^{\circ} \mathrm{W} 0^{\circ}$ (d) JJA Eoii ${ }^{400}-E^{280}$

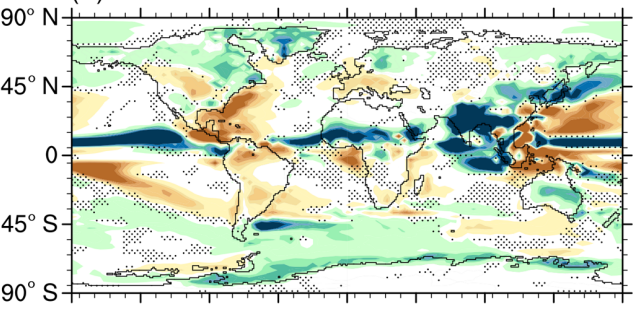

$045^{\circ} \mathrm{E} 90^{\circ} \mathrm{E} 135^{\circ} \mathrm{E} 180^{\circ} 135^{\circ} \mathrm{W} 90^{\circ} \mathrm{W} 45^{\circ} \mathrm{W} \quad 0^{\circ}$ (f) DJF $\mathrm{Eoi}^{400}-\mathrm{E}^{280}$



$045^{\circ} \mathrm{E} 90^{\circ} \mathrm{E} 135^{\circ} \mathrm{E} 180^{\circ} 135^{\circ} \mathrm{W} 90^{\circ} \mathrm{W} 45^{\circ} \mathrm{W} \quad 0^{\circ}$

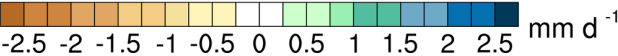

Figure 6. Mean annual and seasonal Pliocene precipitation anomalies. (a) Annual Eoi ${ }^{280}-\mathrm{E}^{280}$, (b) annual Eoi ${ }^{400}-\mathrm{E}^{280}$, (c) JJA Eoi ${ }^{280}$ $\mathrm{E}^{280}$, (d) JJA Eoi ${ }^{400}-\mathrm{E}^{280}$, (e) DJF Eoi ${ }^{280}-\mathrm{E}^{280}$ and (f) DJF Eoi ${ }^{400}-\mathrm{E}^{280}$. Stippling indicates regions in which results are not statistically significant at a $95 \%$ confidence criterion.

Table 5. Climatological zonal mean core latitude of the subtropical jet (StJ) for $\mathrm{E}^{280}$, Eoi ${ }^{280}$ and Eoi ${ }^{400}$ experiments during DecemberJanuary-February (DJF) and June-July-August (JJA) seasons. Note that only the StJ is reported as it is more stable and persistent than the polar jet.

\begin{tabular}{lrrrr}
\hline ID & NH DJF $\left({ }^{\circ} \mathrm{N}\right)$ & NH JJA $\left({ }^{\circ} \mathrm{N}\right)$ & SH DJF $\left({ }^{\circ} \mathrm{S}\right)$ & SH JJA $\left({ }^{\circ} \mathrm{S}\right)$ \\
\hline Eoi $^{400}$ & $32.8 \pm 1.5$ & $47.0 \pm 2.4$ & $44.8 \pm 1.9$ & $33.9 \pm 1.3$ \\
Eoi $^{280}$ & $32.0 \pm 1.1$ & $46.2 \pm 1.9$ & $44.7 \pm 1.8$ & $33.7 \pm 1.5$ \\
$\mathrm{E}^{280}$ & $30.3 \pm 1.4$ & $44.6 \pm 3.0$ & $42.5 \pm 1.3$ & $33.5 \pm 1.8$ \\
\hline
\end{tabular}

ography should be driven by steepening (shallowing) of the tropical meridional temperature gradients in the tropics south (north) of the ITCZ. Coincident with the change in land surface and geography (Eoi $\left.{ }^{280}-\mathrm{E}^{280}\right)$ is a weakening of the combined annual mean overturning within the two Hadley cells (191 and $180 \times 10^{9} \mathrm{~kg} \mathrm{~s}^{-1}$ for $\mathrm{E}^{280}$ and $\mathrm{Eoi}^{280}$, respectively).

The wintertime subtropical jet (StJ; also known as the midlatitude jet) and polar jet (PJ) are shown within Fig. 8 . We characterise the mean spatial envelope of the jet path by deriving, from 50 years of daily data, the days per sea- son in which the mean mass-weighted flow speed integrated over $400-100 \mathrm{hPa}(\sim 7-16 \mathrm{~km})$ exceeds $30 \mathrm{~ms}^{-1}$. For both $\mathrm{E}^{280}$ (Fig. 8a-d) and $\mathrm{E}^{400}$ (not shown), we obtain a seasonal jet stream configuration which is consistent with the ERA-40 and derived results of Archer and Caldeira (2008). The PJ and the StJ streams can be difficult to differentiate as the former is latitudinally irregular, so following Koch et al. (2006) we use normalised wind shear as a height differentiator. The StJ stream path is more persistent and stable and so is characterised by the mean latitude of the StJ 
(a) $\mathrm{E}^{280}$

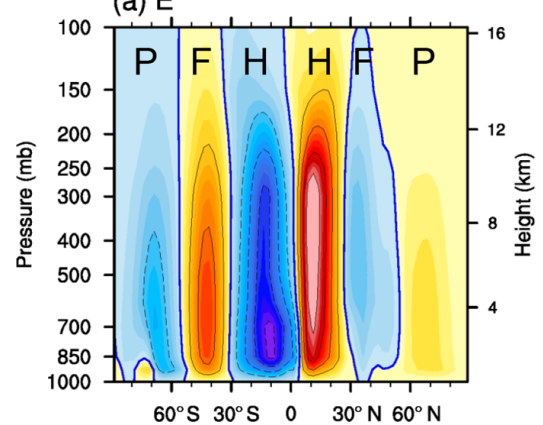

$60^{\circ} \mathrm{S} 30^{\circ} \mathrm{S} \quad 0 \quad 30^{\circ} \mathrm{N} 60^{\circ} \mathrm{N}$ (b) Eoi ${ }^{280}$

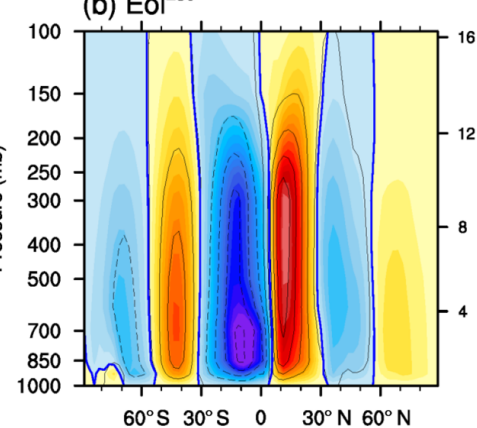

(c) $\mathrm{Eoi}^{400}$

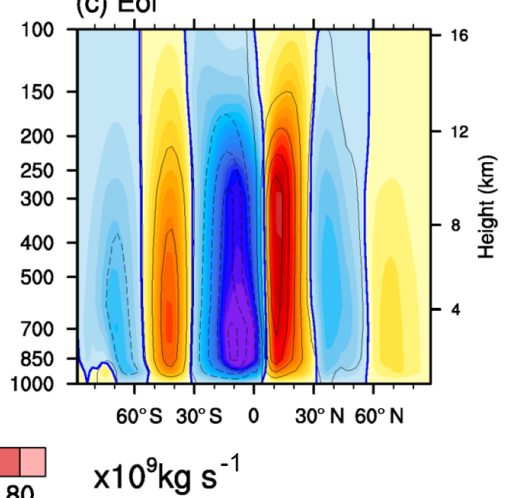

Figure 7. Mean annual zonally averaged meridional mass transport streamfunction for (a) $\mathrm{E}^{280}$, (b) Eoi ${ }^{280}$ and (c) Eoi ${ }^{400}$. The contour lines are from $\mathrm{E}^{280}$ and are shown for intervals of $2 \times 10^{10} \mathrm{~kg} \mathrm{~s}^{-1}$ with dashed lines indicating anticlockwise (looking westward) circulation (ascending air moves southward). The solid blue contour indicates zero meridional streamfunction indicative of the boundary of circulation cells. The Hadley (H), Ferrel (F) and the polar (P) cells are indicated within panel (a).

Table 6. Global mean annual sea surface temperature (MASST) and various metrics for the spatial extent of the equatorial warm pool regions.

\begin{tabular}{lrrrr}
\hline ID & $\begin{array}{r}\text { MASST } \\
\left({ }^{\circ} \mathrm{C}\right)\end{array}$ & $\begin{array}{r}\text { GWP } \\
\left(\times 10^{6} \mathrm{~km}^{2}\right)\end{array}$ & $\begin{array}{r}\text { WHWP }_{\max } \\
\left(\times 10^{6} \mathrm{~km}^{2}\right)\end{array}$ & $\begin{array}{r}\text { IPWP } \max (\text { year round }) \\
\left(\times 10^{6} \mathrm{~km}^{2}\right)\end{array}$ \\
\hline Eoi $^{450}$ & $20.3 \pm 0.1$ & $107.5 \pm 2.5$ & $25.2 \pm 0.6$ & $95.7 \pm 2.8[63.0 \pm 2.8]$ \\
Eoi $^{400}$ & $19.9 \pm 0.1$ & $99.7 \pm 2.6$ & $24.4 \pm 0.5$ & $89.0 \pm 3.3[57.1 \pm 2.1]$ \\
orb Eoi $^{400}$ & $19.8 \pm 0.1$ & $98.5 \pm 2.8$ & $23.8 \pm 0.5$ & $87.4 \pm 3.0[56.2 \pm 1.9]$ \\
Eoi $^{350}$ & $19.6 \pm 0.1$ & $92.1 \pm 3.1$ & $23.1 \pm 0.5$ & $82.4 \pm 3.7[50.9 \pm 2.6]$ \\
Eoi $^{280}$ & $18.9 \pm 0.1$ & $78.8 \pm 2.9$ & $19.7 \pm 1.2$ & $71.7 \pm 3.0[38.6 \pm 3.3]$ \\
E $^{280}$ & $18.1 \pm 0.1$ & $66.4 \pm 4.5$ & $15.0 \pm 1.5$ & $62.8 \pm 3.9[25.4 \pm 3.1]$ \\
$\mathrm{E}^{400}$ & $19.3 \pm 0.1$ & $91.5 \pm 3.3$ & $22.1 \pm 1.3$ & $85.6 \pm 3.9[50.8 \pm 3.2]$ \\
$\mathrm{E}^{560}$ & $20.4 \pm 0.1$ & $117.2 \pm 3.3$ & $27.2 \pm 1.5$ & $102.9 \pm 2.5[68.9 \pm 2.6]$ \\
\hline
\end{tabular}

The global warm pool (GWP) area defined using MASST and a $28^{\circ} \mathrm{C}$ criterion. Western Hemisphere warm pool (WHWP; $130-45^{\circ} \mathrm{W}$ ) and Indo-Pacific warm pool (IPWP; $30^{\circ} \mathrm{E}-60^{\circ} \mathrm{W}$ ) are defined as the max

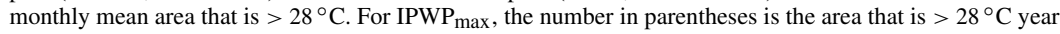
round.

core which is shown within Table 5. The change in geography $\left(\mathrm{Eoi}^{280}-\mathrm{E}^{280}\right)$ drives a poleward shift of the mean StJ latitude of $\sim 1.6^{\circ}$ in the Northern Hemisphere (both seasons) and $2.2^{\circ}$ in the Southern Hemisphere summer. The response to Pliocene $\mathrm{CO}_{2}\left(\mathrm{Eoi}^{400}-\mathrm{Eoi}^{280}\right)$ increase is weaker with a $0.8^{\circ}$ poleward shift of the mean StJ latitude in the Northern Hemisphere (both seasons). The Southern Hemisphere mean StJ appears only weakly poleward shifting in response to Pliocene $\mathrm{CO}_{2}$ increase. Regionally, jet behaviour deviates from the global mean view. Within the North Atlantic, the PJ moves equatorward in response to the change in palaeogeography $\left(\mathrm{Eoi}^{280}-\mathrm{E}^{280}\right)$ moving the jet stream mean path from northern to southern Europe (Fig. 8b vs. 8f). Synoptic storms grow and propagate along jet stream axes, and so this equatorward shift in the PJ likely contributes to the increase in rainfall seen in southern Europe during Pliocene wintertime (Fig. 6e vs. 6f).

\subsection{State of the ocean climatology}

\subsubsection{Sea surface temperature and warm pools}

Modelled mean annual SSTs (MASSTs) are detailed within Table 6 and Pliocene anomalies are shown within Fig. 9. We see a $0.8^{\circ} \mathrm{C}$ warming due to the change in palaeogeography $\left(\mathrm{Eoi}^{280}-\mathrm{E}^{280}\right)$ and a further $1.0^{\circ} \mathrm{C}$ of warming due to the change in Pliocene $\mathrm{CO}_{2}\left(\mathrm{Eoi}^{400}-\mathrm{Eoi}^{280}\right)$. With increasing levels of $\mathrm{CO}_{2}$, regional patterns of MASST change due to palaeogeography are overprinted by $\mathrm{CO}_{2}$-induced warming which is most evident in the midlatitudes. The greatest warming occurs within the North Atlantic subpolar gyre where $\mathrm{Eoi}^{400}-\mathrm{E}^{280}$ reaches $9.3^{\circ} \mathrm{C}$. In the vicinity of the modern Gulf Stream and North Atlantic Drift, we find a cooling during DJF and MAM seasons of up to $-4.9^{\circ} \mathrm{C}$ within Eoi $^{280}$ $\mathrm{E}^{280}$ (not shown). Investigation of surface ocean velocity vectors (not shown) suggests an intensification of the North Atlantic wind-driven subpolar gyre which appears to disrupt western intensification and the path of the Gulf Stream. The 
(a) DJF StJ Lat $\mathrm{E}^{280}$

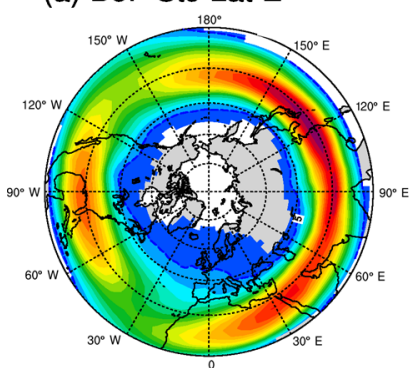

(e) DJF StJ Eoi ${ }^{280}$

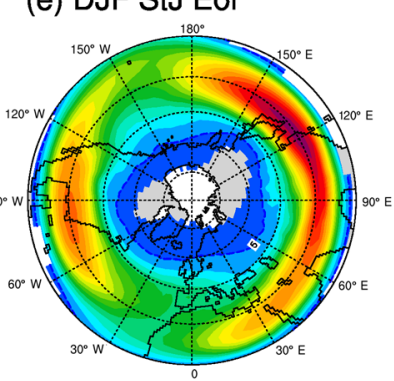

(i) DJF StJ Eoji ${ }^{400}$

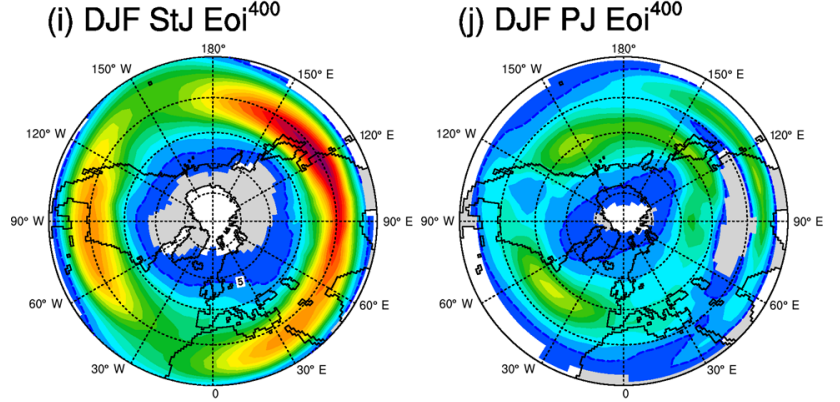

(b) DJF PJ E ${ }^{280}$

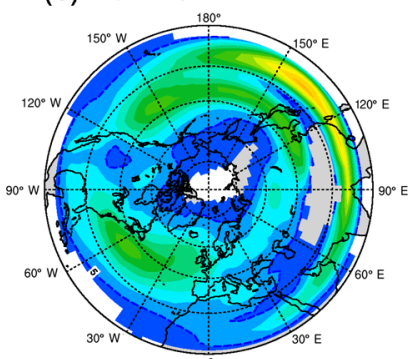

(f) DJF PJ Eoi ${ }^{280}$

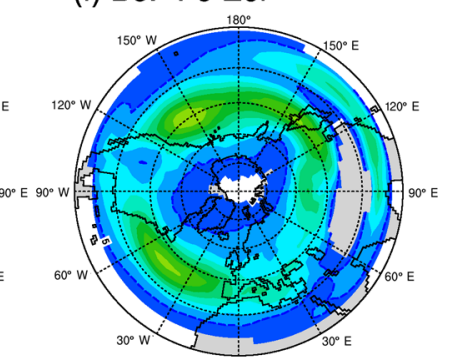

(j) DJF PJ Eoii ${ }^{400}$ (c) JJA StJ $E^{280}$

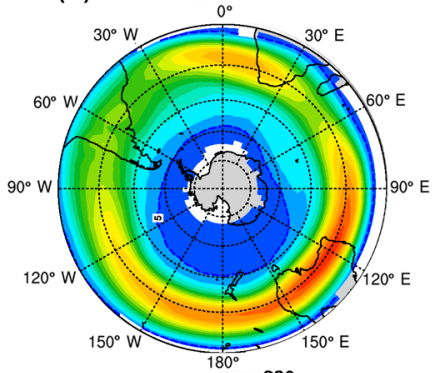

(g) JJA StJ Eoi ${ }^{180}$

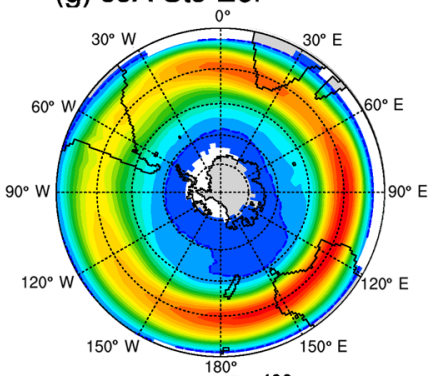

(k) JJA StJ Eoj ${ }^{1800}$

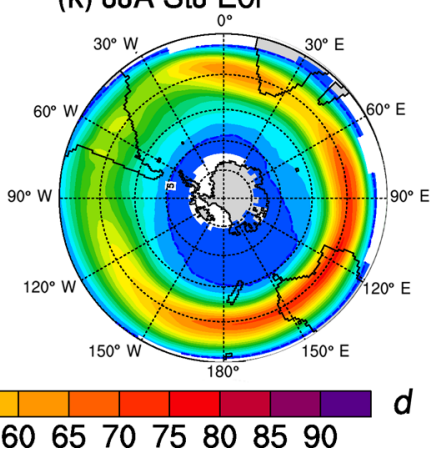

(d) JJA PJ E E $^{280}$

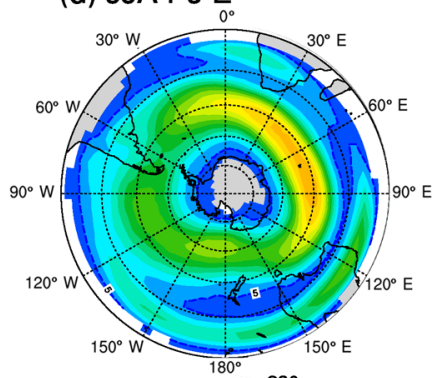

(h) JJA PJ ${ }^{180^{280}}$

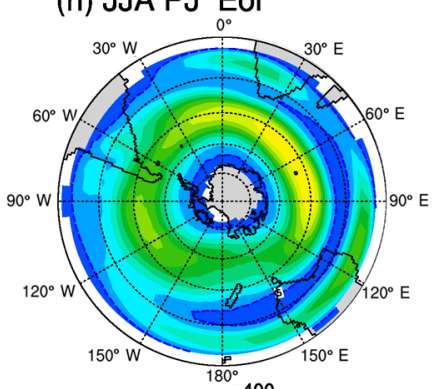

(l) JJA PJ Eoi ${ }^{400}$

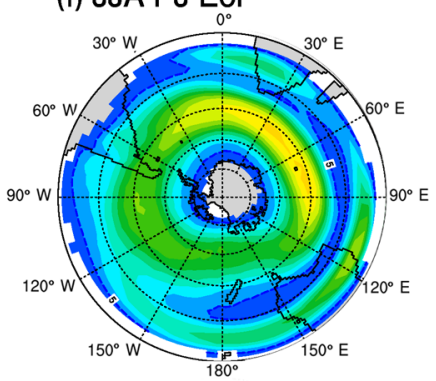

$\begin{array}{lllllllllllllllllll}0 & 5 & 10 & 15 & 20 & 25 & 30 & 35 & 40 & 45 & 50 & 55 & 60 & 65 & 70 & 75 & 80 & 85 & 90\end{array}$

Figure 8. Seasonal (DJF and JJA) distribution of the StJ and PJ streams for (a-d) $\mathrm{E}^{280}$, (e-h) Eoi ${ }^{280}$ and (i-l) Eoi ${ }^{400}$. Colour scale indicates the mean number of days within a season in which wind speed is $>30 \mathrm{~ms}^{-1}$ over $400-100 \mathrm{hPa}$. Note that the wind-shear PJ classification identifies a jet downstream of the Himalayas.

westerlies in the region appear to intercept the remnant Gulf Stream and divert it from a northeasterly to a more eastward path. This is seen as the warm tongue south of the extant Gulf Stream (Fig. 9). A similar expression of MASST within the North Atlantic was seen by Chandler et al. (2013), and characteristic signatures may be present within other PlioMIP1 experiments (e.g. Fig. 1 of Dowsett et al., 2013). A persistent cooling is also found within the Barents Sea region coincident with the surface air temperature anomalies discussed within Sect. 4.1.1.

Table 6 also details the size of the global and component equatorial warm pools within the pre-industrial and Pliocene experiments. We see an expansion of the globally integrated warm pool with the change in palaeogeography (Eoi ${ }^{280}$ $\mathrm{E}^{280}$ ). This is evident in both the Western Hemisphere warm pool (WHWP) and Indo-Pacific warm pool (IPWP) regions. As expected, increased $\mathrm{CO}_{2}$ drives warm pool expansion under both modern and Pliocene geographic conditions.

\subsubsection{Sea ice}

A complex picture emerges in the sensitivity of seasonal sea ice distribution to geographic and $\mathrm{CO}_{2}$ changes as shown within Fig. 10. Within the Northern Hemisphere winter, the palaeogeography changes drive an equatorward expansion of sea ice in the Greenland Sea region. Increasing $\mathrm{CO}_{2}$ from 280 to $400 \mathrm{ppm}$ counteracts some of this expansion. In the Southern Hemisphere, the palaeogeographical changes suppress sea ice extent significantly within the Weddell Sea and also eastward towards the Davis Sea in both summer and winter. Coincident with this suppression is an equatorward expansion of sea ice within the Bellingshausen Sea region. As we increase $\mathrm{CO}_{2}$, we see a general reduction in the sea ice extent and concentration in both summer and winter months. Within $\mathrm{Eoi}^{400}$ boreal summer, the Arctic is largely ice-free and the ice that is present is mostly $<50 \%$ concentration. During austral summer, the concentration of sea ice within 
(a) ANN Eoi ${ }^{450}-E^{280}$

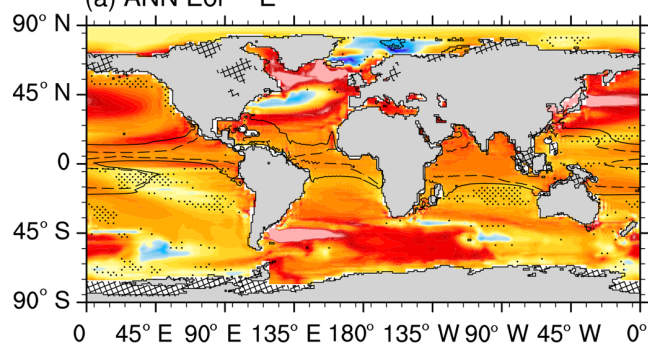

(c) ANN Eoi ${ }^{350}-E^{280}$

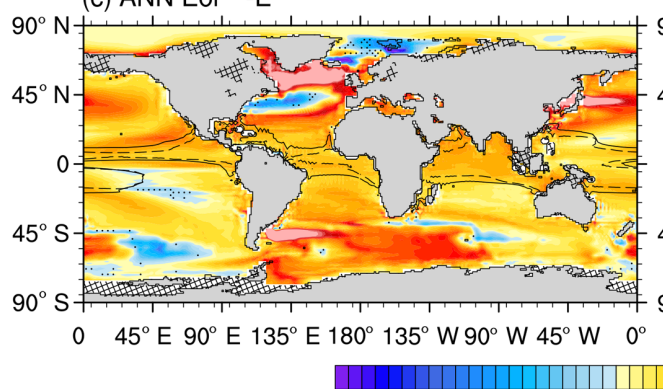

(b) ANN $\mathrm{Eoi}^{400}-\mathrm{E}^{280}$

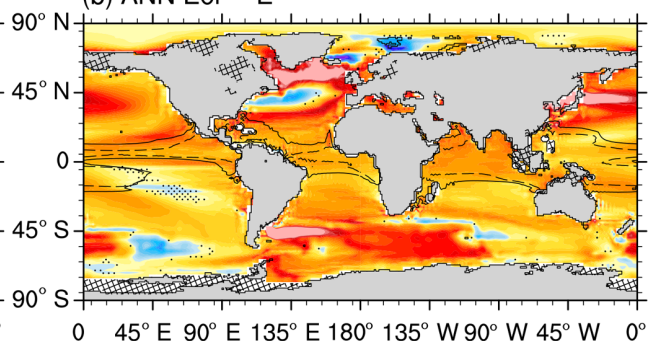

(d) ANN Eoi ${ }^{280}-\mathrm{E}^{280}$
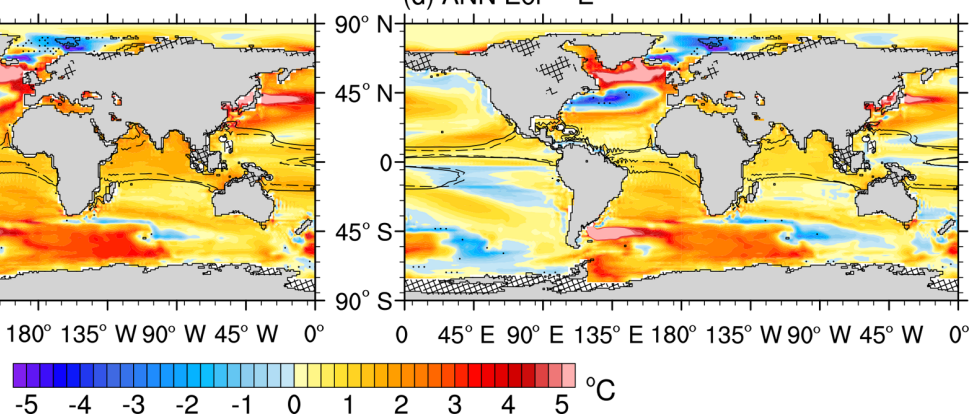

Figure 9. Pliocene MASST anomalies against $E^{280}$. (a) $\mathrm{Eoi}^{450}-\mathrm{E}^{280}$, (b) $\mathrm{Eoi}^{400}-\mathrm{E}^{280}$, (c) $\mathrm{Eoi}^{350}-\mathrm{E}^{280}$ and (d) $\mathrm{Eoi}^{280}-\mathrm{E}^{280}$. Dotted contour lines indicate $\mathrm{E}^{280} 28^{\circ} \mathrm{C}$ warm pool, whilst the solid contour indicates the Pliocene $28^{\circ} \mathrm{C}$ warm pool. Cross hatching indicates regions in which either modern or Pliocene experiments have contrasting land surface. Stippling indicates regions in which there is no statistical difference at a $95 \%$ confidence criterion.

Table 7. Characteristics of the Atlantic and Pacific meridional overturning circulations (AMOC and PMOC).

\begin{tabular}{|c|c|c|c|c|}
\hline ID & $\mathrm{AMOC}_{\max }(\mathrm{Sv})$ & $\mathrm{AMOC}_{\max } 26.5^{\circ} \mathrm{N}(\mathrm{Sv})$ & $\mathrm{PMOC}_{+\mathrm{ve}}(\mathrm{Sv})$ & $\begin{array}{r}\text { PMOC }- \text { ve }(\mathrm{Sv})[\text { Depth; } \mathrm{m}] \\
\mathrm{PDW}\left(\geq 30^{\circ} \mathrm{S} \text { below } 500 \mathrm{~m}\right)\end{array}$ \\
\hline Eoi $^{450}$ & $18.6 \pm 1.1$ & $16.3 \pm 1.0$ & $39.3 \pm 4.0$ & $-9.3 \pm 1.5[1000]$ \\
\hline Eoi $^{400}$ & $19.6 \pm 1.0$ & $17.2 \pm 0.8$ & $40.6 \pm 3.0$ & $-9.1 \pm 1.4[1000]$ \\
\hline orb Eoi $^{400}$ & $21.4 \pm 1.5$ & $19.3 \pm 1.1$ & $40.9 \pm 3.3$ & $-9.8 \pm 1.9[1000]$ \\
\hline Eoi $^{350}$ & $20.4 \pm 1.1$ & $18.8 \pm 0.9$ & $42.2 \pm 3.9$ & $-9.8 \pm 1.8[1000]$ \\
\hline Eoi $^{280}$ & $18.9 \pm 0.8$ & $17.4 \pm 0.9$ & $46.0 \pm 3.4$ & $-12.3 \pm 1.6[1500]$ \\
\hline$E^{280}$ & $15.7 \pm 1.2$ & $13.4 \pm 1.1$ & $33.4 \pm 3.1$ & $-8.6 \pm 1.4[2700]$ \\
\hline$E^{400}$ & $15.2 \pm 1.2$ & $13.6 \pm 1.0$ & $29.3 \pm 2.5$ & $-9.0 \pm 0.9[3960]$ \\
\hline$E^{560}$ & $15.9 \pm 1.3$ & $13.8 \pm 0.9$ & $25.0 \pm 2.1$ & $7.6 \pm 0.8[3960]$ \\
\hline
\end{tabular}

$\mathrm{AMOC}_{\mathrm{max}}$ is the maximum AMOC. PMOC + ve reflects the subtropical gyre circulation, whilst PMOC-ve reflects the Pacific Deep Water (PDW) and North Pacific Deep Water (NPDW).

the Pliocene is reduced in extent and more zonally asymmetric, concentrated within the Amundsen and Ross seas.

\subsubsection{Mixed layer depth and deep-water formation}

The mixed layer depth (MLD) for $\mathrm{E}^{280}$, Eoi ${ }^{280}$ and Eoi ${ }^{400}$ is shown within Fig. 11. We focus on deep convection, the principle mechanism of deep-water formation. Deep convection is highly localised, and therefore model representation is only suggestive. Nevertheless, $\mathrm{E}^{280}$ represents reasonably well the modern open-ocean deep convection that occurs within the Weddell and Ross seas (which form the main formation sites of AABW) and in the Labrador, Irminger and Greenland seas. All Pliocene experiments exhibit more widespread deep convection particularly within the Labrador and Norwegian seas, and near the Antarctic Peninsula island. In contrast to Burls et al. (2017), we do not model any significant increase in Pliocene North Pacific MLD and hence no subsequent intensification of North Pacific Deep Water (NPDW) formation (Table 7 and Fig. 11).

\subsubsection{Ocean heat and mass transport (Atlantic and Pacific MOCs)}

The Atlantic meridional overturning circulation (AMOC) streamfunctions for $\mathrm{E}^{280}$, $\mathrm{Eoi}^{280}$ and $\mathrm{Eoi}^{400}$ are shown within Fig. 12 and detailed within Table 7. The pre-industrial experiment $\mathrm{E}^{280}$ has a maximum AMOC strength at $26.5^{\circ} \mathrm{N}$ of 


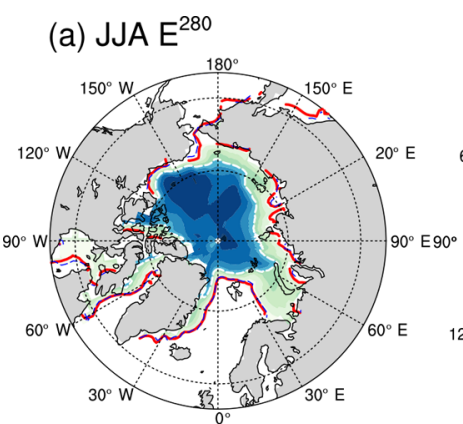

(e) JJA Eoi ${ }^{280}$

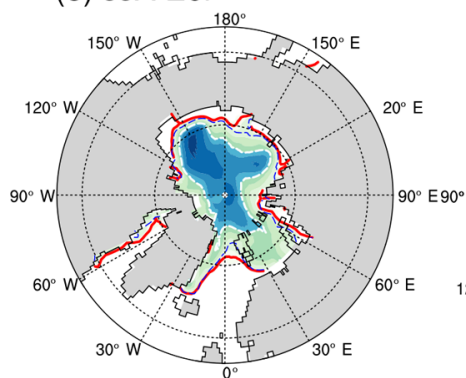

(i) JJA Eoi ${ }^{400^{\circ}}$ (b) JJA E $E^{280}$

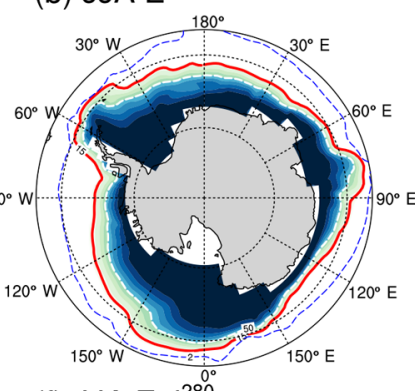

(f) JJA Eoi ${ }^{280}$ (c) DJF E $E^{280}$



(g) DJF Eoi ${ }^{280}$ (d) DJF E $E^{280}$

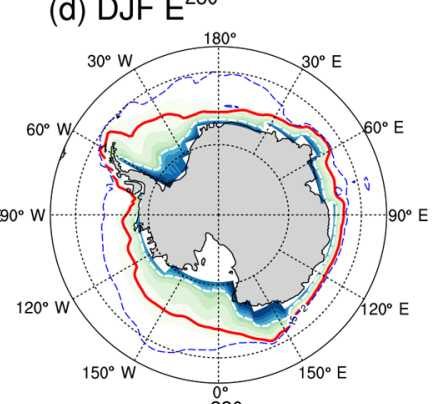

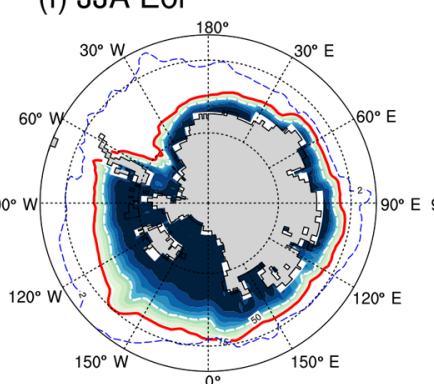

(j) JJA Eoi ${ }^{400^{\circ}}$

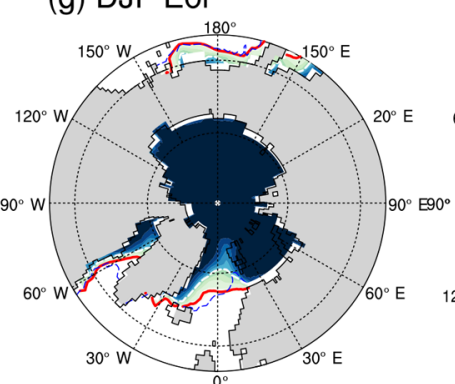

(k) DJF Eoi ${ }^{400}$ (h) DJF Eoi $i^{280}$

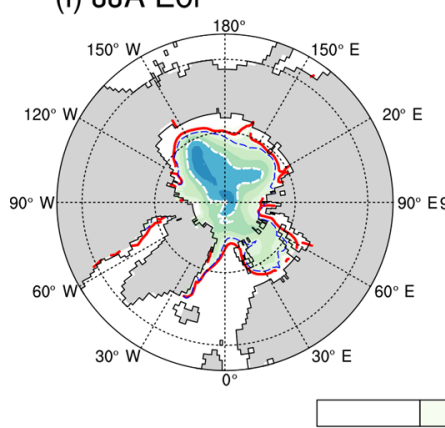

(j) JJA Eoi ${ }^{400}$
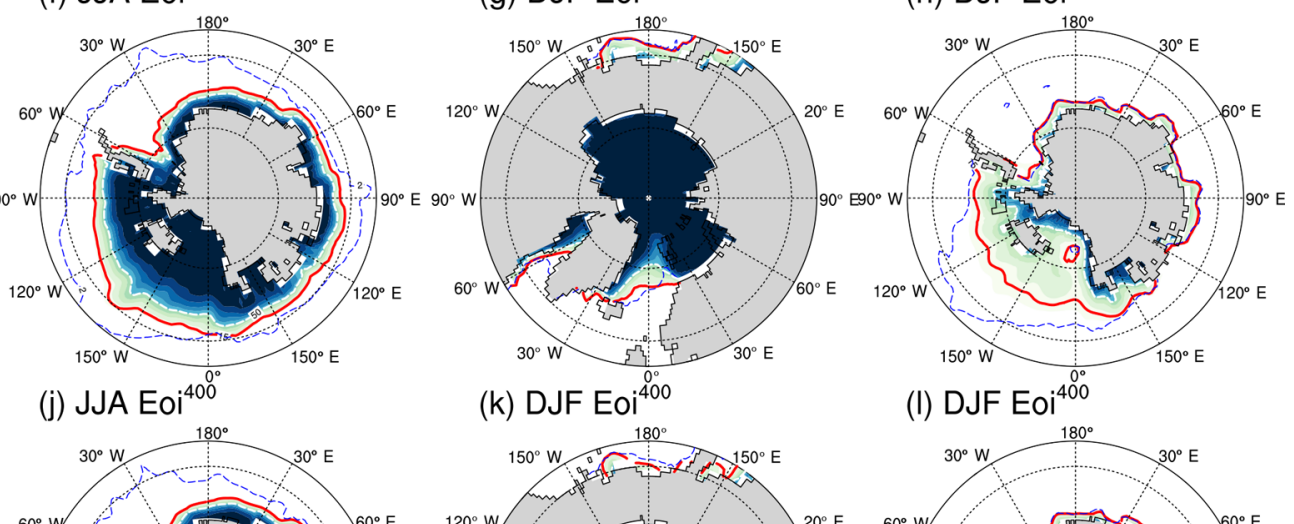

(I) DJF Eoi ${ }^{400}$

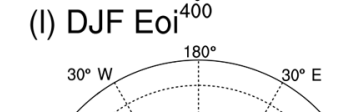

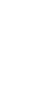

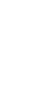

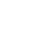




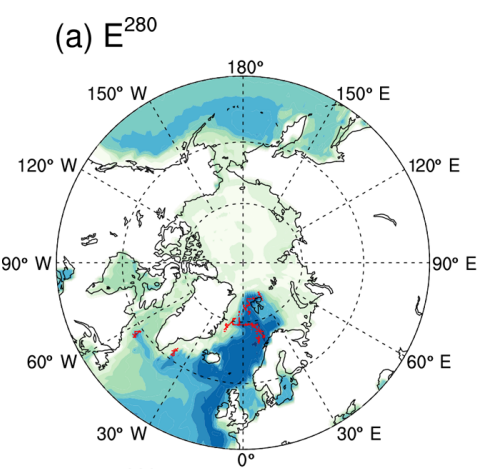

(d) $E^{280}$

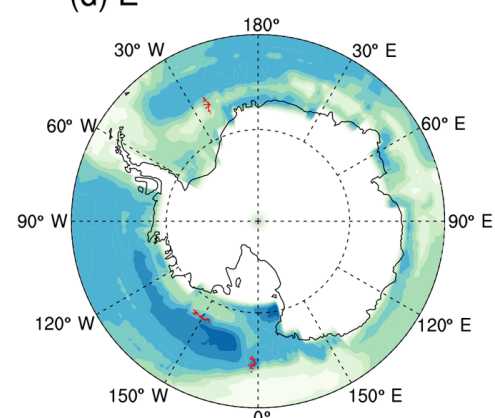

(b) $\mathrm{Eoi}^{280}$

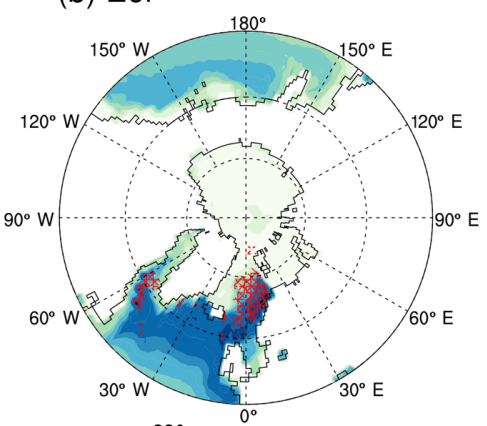

(e) $\mathrm{Eoi}^{280}$

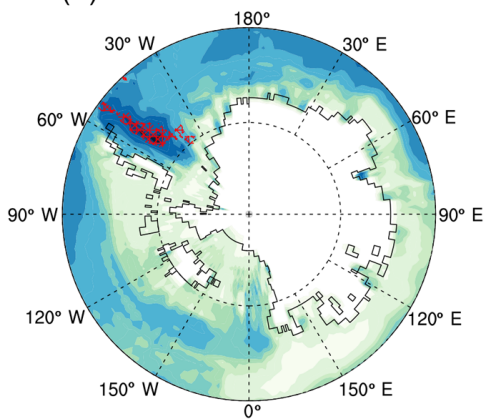

(c) $\mathrm{Eoi}^{400}$

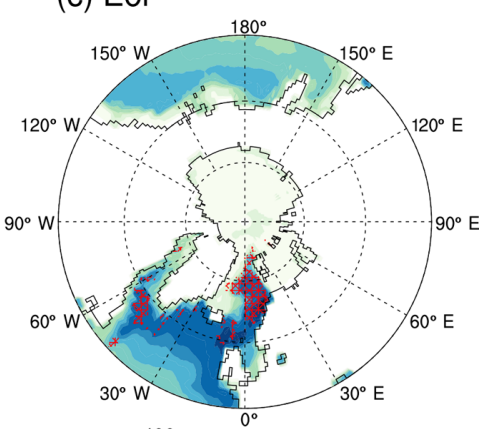

(f) $\mathrm{Eoi}^{400}$

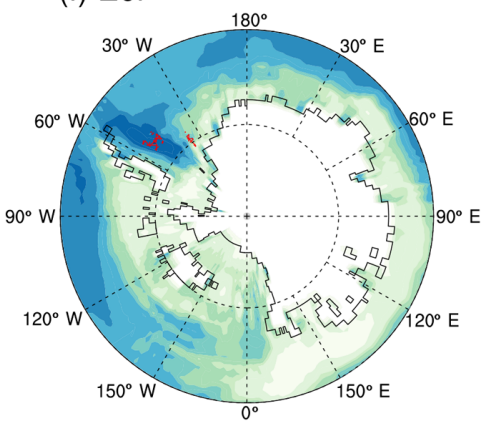

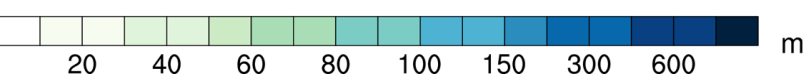

Figure 11. Mean March Northern Hemisphere and September Southern Hemisphere mixed layer depth for (a, d) $\mathrm{E}^{280}$, (b, e) Eoi ${ }^{280}$ and (c, f) $\mathrm{Eoi}^{400}$. Red hashes indicate regions that exhibit deep $(>1000 \mathrm{~m})$ convection at least 1 month during the climatological averaging period; single-cell ocean regions have been expanded slightly to improve visualisation.

(a) $E^{280}$

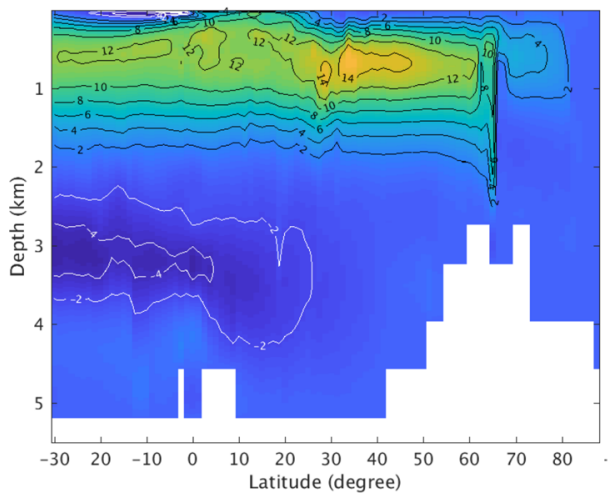

(b) Eoi 280

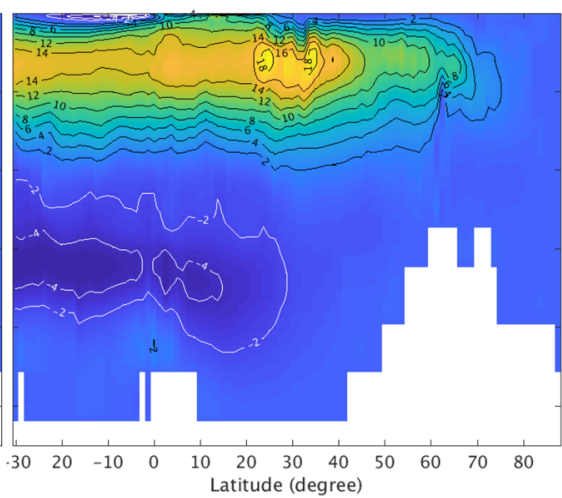

(c) $\mathrm{Eoi}^{400}$

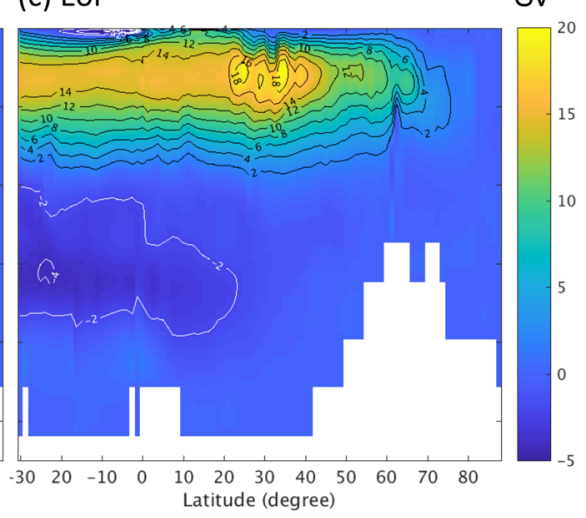

Figure 12. Time-averaged Atlantic overturning circulation for (a) $\mathrm{E}^{280}$, (b) $\mathrm{Eoi}^{280}$ and (c) Eoi ${ }^{400}$. Positive values indicate clockwise circulation.

NPDW. Pliocene palaeogeography $\left(\mathrm{Eoi}^{280}-\mathrm{E}^{280}\right)$ drives an intensification of both the subtropical gyre and PDW overturning, whilst increasing $\mathrm{CO}_{2}$ acts to weaken them. The Pliocene subtropical gyre $\left(\mathrm{PMOC}_{+\mathrm{ve}}\right)$ and PDW $\left(\mathrm{PMOC}_{-\mathrm{ve}}\right)$ overturning are stronger regardless of $\mathrm{CO}_{2}$ level (e.g. within $\mathrm{Eoi}^{400}, \mathrm{PMOC}_{+\mathrm{ve}}$ and $\mathrm{PMOC}_{-\mathrm{ve}}$ are $22 \%$ and $6 \%$ stronger than $\mathrm{E}^{280}$ ). With the change in palaeogeography (Eoi ${ }^{280}$ $\mathrm{E}^{280}$ ), the PDW shoals (from $\sim 4$ to $3 \mathrm{~km}$ ) and with increasing Pliocene $\mathrm{CO}_{2}$ the NPDW overturning reduces in north- ward reach, associated with the warming of North Pacific MASST (Fig. 9).

\subsubsection{Antarctic Circumpolar Current}

The Antarctic Circumpolar Current (ACC) strength is detailed within Table 8 and shown within Fig. 14. We calculate the volumetric flow of the ACC at the Drake Passage across a $64.4-56.9^{\circ} \mathrm{S}, 65^{\circ} \mathrm{W}$, transect using the positive as- 
(a) $\mathrm{E}^{280}$

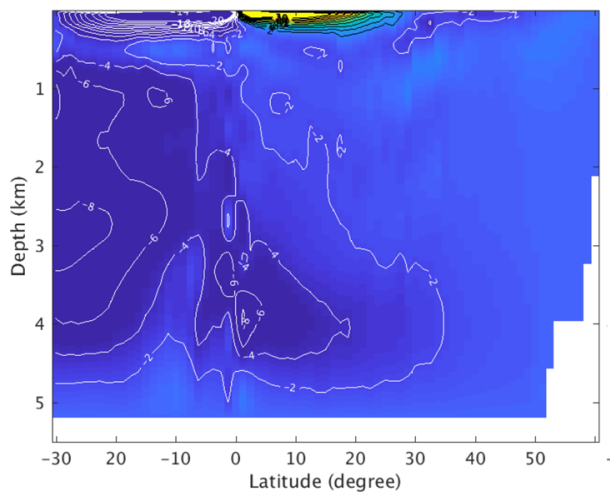

(b) Eoi 280

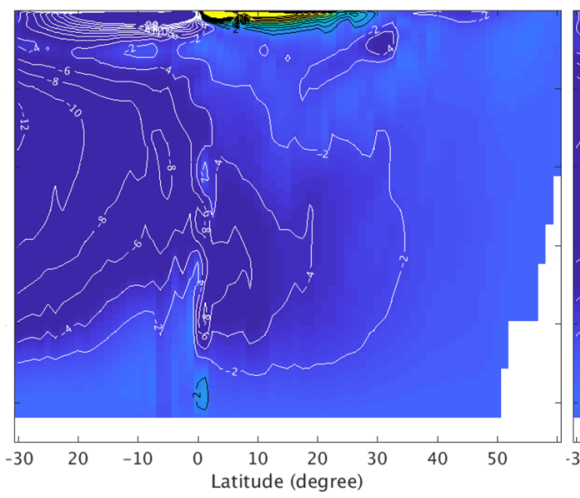

(c) Eoi 400

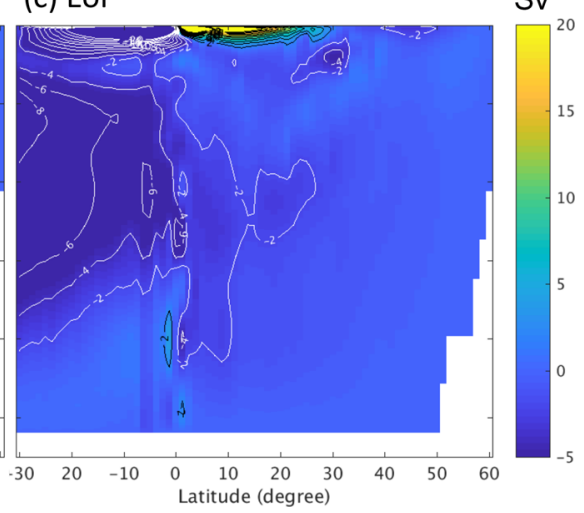

Figure 13. Time-averaged Pacific overturning circulation for (a) $\mathrm{E}^{280}$, (b) $\mathrm{Eoi}^{280}$ and (c) Eoi ${ }^{400}$. Positive values indicate clockwise circulation.

Table 8. Characteristics of the Antarctic Circumpolar Current (ACC) within the Pliocene and pre-industrial experiments. From the barotropic streamfunction, we derive the mean ACC latitude (the polar front) from the centroid of the zonal transport and the core width from the $\pm 50 \%$ boundary.

\begin{tabular}{|c|c|c|c|}
\hline ID & $\begin{array}{r}\mathrm{ACC} \text { at } 65^{\circ} \mathrm{W} \\
(\mathrm{Sv})\end{array}$ & $\begin{array}{r}\text { Mean ACC } \\
\text { latitude }\left({ }^{\circ} \mathrm{S}\right)\end{array}$ & $\begin{array}{r}\text { Mean ACC core } \\
\text { width }\left({ }^{\circ}\right)\end{array}$ \\
\hline Eoi $^{450}$ & $78.3 \pm 2.9$ & 58.8 & 11.5 \\
\hline Eoi $^{400}$ & $76.7 \pm 2.8$ & 58.8 & 11.8 \\
\hline orb Eoi $^{400}$ & $77.3 \pm 2.9$ & 58.7 & 11.8 \\
\hline Eoi $^{350}$ & $73.5 \pm 3.0$ & 58.8 & 11.9 \\
\hline Eoi $^{280}$ & $51.6 \pm 31.9$ & 60.0 & 12.6 \\
\hline $\mathrm{E}^{280}$ & $179.0 \pm 11.2$ & 66.0 & 33.6 \\
\hline$E^{400}$ & $186.6 \pm 9.0$ & 66.6 & 33.3 \\
\hline
\end{tabular}

pect of the $U$ component (zonal) of the total (barotropic and baroclinic) velocity. We find an overly intense ACC within $\mathrm{E}^{280}$ and $\mathrm{E}^{400}$ when compared against recent observations of 134-164 Sv (Cunningham et al., 2003; Griesel et al., 2012). The overly intense ACC within HadCM3 has been identified previously. Meijers et al. (2012) compared CMIP5 historical experiments to observations and found the model's ACC flow at the Drake Passage transect of $244.5 \pm 4.0 \mathrm{~Sv}$ compared unfavourably to observations and $155 \pm 51 \mathrm{~Sv}$ of the CMIP5 multi-model mean. This unrealistic intensity appeared to be driven, or at least connected to, an overly strong salinity gradient across the ACC, particularly towards low latitudes (Meijers et al., 2012). This could be a consequence of the artificial freshwater correction field used within the CMIP5 historical and piControl experiments and $\mathrm{E}^{280}$ here.

Modelled ACC strength appears significantly reduced within the Pliocene experiments. Westerlies intensify in the Southern Hemisphere within the Pliocene but mostly in regions poleward of the Sub-Antarctic front (poleward of the ACC). The weakened Drake Passage throughflow is mirrored within the vertically integrated barotropic streamfunction. Care must be taken when interpreting ACC strength in situations of changed palaeogeography and island specification. The ACC is weakly stratified and vertically coherent and so is dominantly barotropic in nature. Within the Pliocene boundary conditions (Sect. 3.2.2), the island peninsula is defined as a separate barotropic island (from the Antarctic continent), and this may be driving the Pliocene reduction in ACC strength. Also, given a more complex line-integral configuration, the model's barotropic solver may not be converging fully towards a solution. The change in island specification may also be responsible for the change in ACC geographical extent shown within Table 8. Defining the streamfunction cross section by the latitudes of the centroid and upper $50 \%$ of zonal transport, we see that the change in geography (from $\mathrm{E}^{280}$ to $\mathrm{Eoi}^{280}$ ) drives a general latitudinal thinning of the ACC extent and an equatorward shift of its centroid.

Within the Pliocene experiments, the ACC runs mostly between the surface and sea floor between 60 and $57^{\circ} \mathrm{S}$, whilst a deeper countercurrent is present closer to the peninsula. In the Pacific, a pronounced thinning of the ACC latitude extent is observed whereby the Sub-Antarctic front moves equatorwards (the subtropical front is mostly unchanged). With the Pliocene geography, there are suggestions that the Antarctic Coastal Current (the countercurrent to the ACC) flows between the peninsula island and the Antarctic land mass. There is uncertainty as smaller islands in this region are unrepresented within the model. Figure 14 also suggests a more continuous coastal current with the Pliocene palaeogeography, particularly between 180 and $90^{\circ} \mathrm{E}$.

\subsection{Sensitivity to external boundary conditions}

\subsubsection{Orbital configuration}

Here, we examine the sensitivity of the Pliocene climate to a different choice of orbital configuration (e.g. modern (default) vs. KM5C at 3.205 Ma). For $\mathrm{Eoi}^{400}$, there is no mean- 


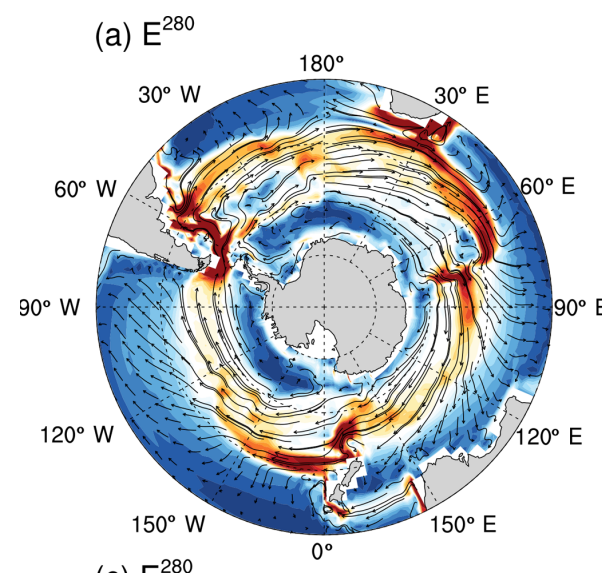

(c) $\mathrm{E}^{280}$

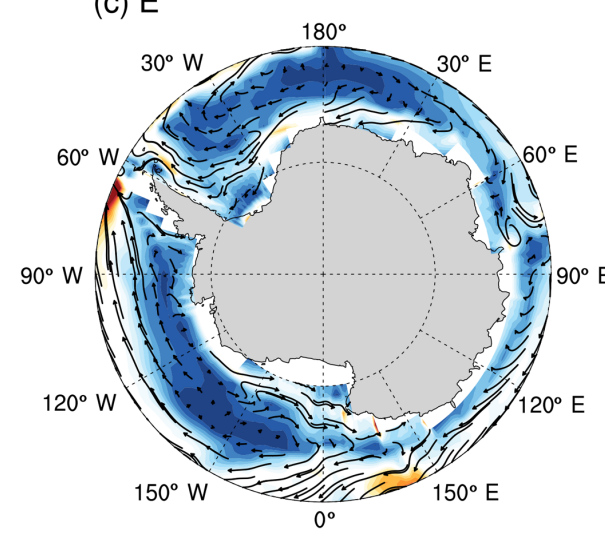

$0^{\circ}$ (b) $\mathrm{Eoi}^{280}$

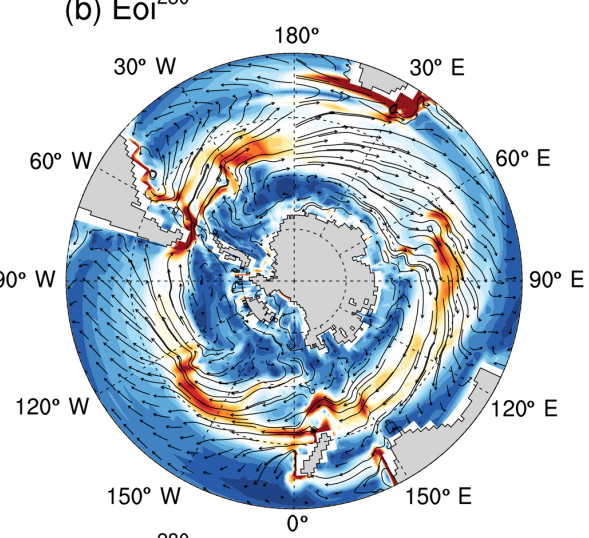

(d) $\mathrm{Eoi}^{280}$

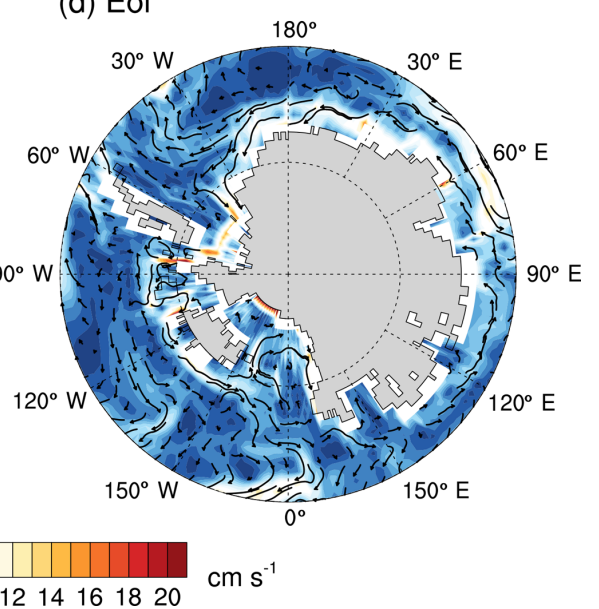

Figure 14. Surface ocean mean annual velocity (streamlines and vector magnitude) for $\mathrm{E}^{280}$ and Eoi ${ }^{280}$. The ACC is shown clearly within (a) $\mathrm{E}^{280}$ and (b) $\mathrm{Eoi}^{280}$, whilst the Antarctic Coastal Current is shown within the close-up plots of (c) $\mathrm{E}^{280}$ and (d) Eoi ${ }^{280}$.

ingful difference in global means (Table 3 MASAT, Table 4 MAP, Table 6 MASST and warm pool areal extent).

There is a statistically significant difference between orb $\mathrm{Eoi}^{400}$ and $\mathrm{Eoi}^{400} \mathrm{AMOC}_{\max }(t(98)=7.20, p \ll 0.0001)$ and $\mathrm{AMOC}$ at $26.5^{\circ} \mathrm{N}(t(98)=11.36, p \ll 0.0001)$ using a two-sample $t$ test assuming unequal variance (null hypothesis being there is no difference in the two time series of annual means). With regards to $\mathrm{PMOC}_{+\mathrm{ve}}$, orb $\mathrm{Eoi}^{400}$ and $\mathrm{Eoi}^{400}$ are deemed equivalent $(t(98)=0.62, p=0.54)$, whilst for $\mathrm{PMOC}_{-\mathrm{ve}}$, the two experiments are equivalent at the $95 \%$ confidence level $(t(98)=1.93, p=0.06)$. Centennial-scale fluctuations in Pliocene $\mathrm{AMOC}_{\max }$ could potentially account for statistical differences between the climatological mean periods of orb $\mathrm{Eoi}^{400}$ and $\mathrm{Eoi}^{400}$, as $\mathrm{AMOC}_{\max }$ differences could simply reflect a lack of coherence introduced since the year 2000 fork point.

\subsubsection{Total solar insolation}

Section 2.1 identified the possibility of different TSI values being used within PlioMIP2 climate models. Here, we determine the sensitivity of HadCM3 within $\mathrm{E}^{280}$ and Eoi ${ }^{400}$ ex- periments to changing the TSI parameter. Reducing total solar insolation from 1365 to $1361 \mathrm{Wm}^{-2}(-0.3 \%)$ reduces the mean incoming solar ( $\mathrm{SW}$ ) radiation averaged over the entire Earth's surface by $1 \mathrm{Wm}^{-2}$ (from 341.25 to $340.25 \mathrm{Wm}^{-2}$ ). Table 9 accumulates climatological indices from $\mathrm{E}^{280}$ and Eoi $^{400}$ under these two TSI values. Figure 15 shows the spatial pattern of climatological differences (Pliocene minus pre-industrial) for simulations based upon 1365 and $1361 \mathrm{Wm}^{-2}$ for MASAT, MAP and MASST. Overall the patterns of climatological anomalies for the experiments using TSI of either 1361 or $1365 \mathrm{Wm}^{-2}$ are very similar. In this sense, comparison of model temperature anomalies to proxy temperature anomalies should not generally be influenced by the choice of TSI.

However, in a similar way to the orbital configuration, $\mathrm{AMOC}_{\text {max }}$ does appear sensitive to TSI when we compare Eoi $^{400}$ against ${ }_{1361}$ Eoi $^{400}(t(98)=-13.3, p \ll .0001)$ and $\mathrm{E}^{280}$ to ${ }_{1361} \mathrm{E}^{280}(t(98)=2.47, p=0.015)$. It is possible that this sensitivity to TSI could be a consequence of the previously described AMOC cyclicity and lack of coherence between Eoi ${ }^{400}$ and ${ }_{1361}$ Eoi $^{400}$. 
Table 9. Sensitivity of $\mathrm{E}^{280}$ and Eoi ${ }^{400}$ (and their corresponding anomalies) to TSI of 1361 and $1365 \mathrm{Wm}^{-2}$. Shown are the mean annual surface air temperature (MASAT), mean annual precipitation (MAP), mean annual sea surface temperature (MASST), Atlantic and Pacific meridional circulations (AMOC $\max$ and $\mathrm{PMOC}_{+\mathrm{ve},-\mathrm{ve}}$; Sect. 4.2.4) and Antarctic Circumpolar Current (ACC; Sect. 4.2.5).

\begin{tabular}{lrrrrrr}
\hline ID & MASAT $\left({ }^{\circ} \mathrm{C}\right)$ & MAP $\left(\mathrm{mmd}^{-1}\right)$ & MASST $\left({ }^{\circ} \mathrm{C}\right)$ & AMOC $_{\max }(\mathrm{Sv})$ & PMOC $_{+\mathrm{ve},-\mathrm{ve}(\mathrm{Sv})}$ & ACC $(\mathrm{Sv})$ \\
\hline $\mathrm{E}^{280}$ & $14.0 \pm 0.1$ & $2.912 \pm 0.008$ & $18.1 \pm 0.1$ & $15.7 \pm 1.2$ & $33.4 \pm 3.1,-8.6 \pm 1.4$ & $179.0 \pm 11.1$ \\
$1361 \mathrm{E}^{280}$ & $13.7 \pm 0.1$ & $2.885 \pm 0.008$ & $17.9 \pm 0.1$ & $16.3 \pm 1.2$ & $33.8 \pm 3.9,-9.2 \pm 1.5$ & $180.0 \pm 6.2$ \\
$\mathrm{Eoi}^{400}$ & $16.9 \pm 0.1$ & $3.025 \pm 0.008$ & $19.9 \pm 0.1$ & $19.6 \pm 1.0$ & $40.6 \pm 3.0,-9.1 \pm 1.4$ & $76.7 \pm 2.8$ \\
$1361 \mathrm{Eoi}^{400}$ & $16.7 \pm 0.1$ & $3.014 \pm 0.010$ & $19.7 \pm 0.1$ & $17.0 \pm 0.9$ & $37.7 \pm 3.3,-8.5 \pm 1.7$ & $76.0 \pm 2.5$ \\
$\mathrm{Eoi}^{400}-\mathrm{E}^{280}$ & $2.9 \pm 0.1$ & $0.113 \pm 0.011$ & $1.8 \pm 0.1$ & $3.9 \pm 1.6$ & $7.2 \pm 4.3,-0.5 \pm 2.0$ & $-102.3 \pm 11.4$ \\
$1361 \mathrm{Eoi}^{400}-1361 \mathrm{E}^{280}$ & $3.0 \pm 0.1$ & $0.129 \pm 0.013$ & $1.8 \pm 0.1$ & $0.7 \pm 1.5$ & $3.9 \pm 5.1,0.7 \pm 1.3$ & $-104.0 \pm 6.7$ \\
\hline
\end{tabular}

(a) MASAT $1365 \mathrm{Wm}^{2} \mathrm{Eoi}^{400}-\mathrm{E}^{280}$

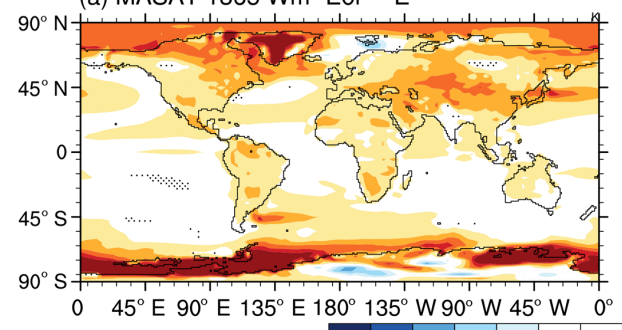

(b) MASAT $1361 \mathrm{Wm}^{2} \mathrm{Eoi}^{400}-\mathrm{E}^{280}$
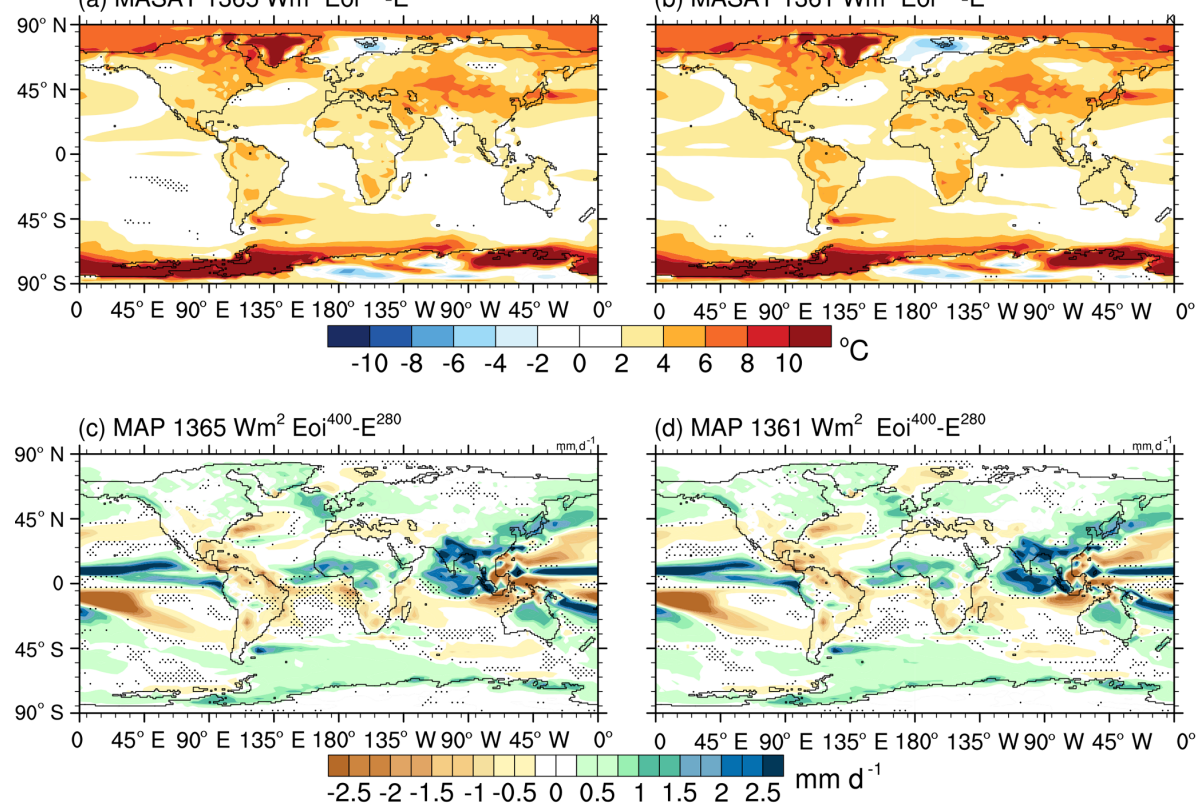

$045^{\circ} \mathrm{E} 90^{\circ} \mathrm{E} 135^{\circ} \mathrm{E} 180^{\circ} 135^{\circ} \mathrm{W} 90^{\circ} \mathrm{W} 45^{\circ} \mathrm{W}-0^{\circ}$

\begin{tabular}{llllllllll|l|l|llll} 
& -10 & -8 & -6 & -4 & -2 & 0 & 2 & 4 & 6 & 8 & 10 & & & \\
\end{tabular}

(e) MASST $1365 \mathrm{Wm}^{2} \mathrm{Eoi}^{400}-\mathrm{E}^{280}$

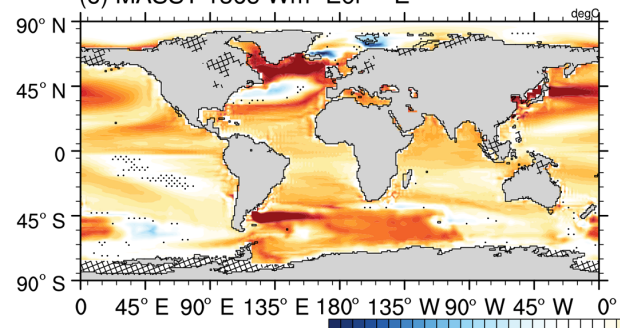

(f) MASST $1361 \mathrm{Wm}^{2} \mathrm{Eoi}^{400}-\mathrm{E}^{280}$

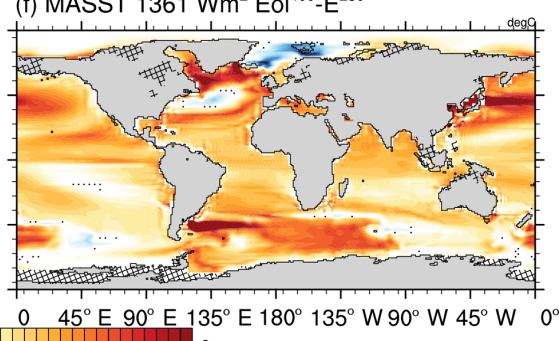

$\begin{array}{cccccccccccc}-5 & -4 & -3 & -2 & -1 & 0 & 1 & 2 & 3 & 4 & 5\end{array}{ }^{\circ} \mathrm{C}$

Figure 15. Sensitivity of Eoi ${ }^{400}-\mathrm{E}^{280}$ anomalies on TSI values for (a, b) MASAT, (c, d) MAP and (e, f) MASST. Stippling indicates regions in which results are not statistically significant at a $95 \%$ confidence criterion.

\section{Discussion}

In this study, we have described the incorporation of PlioMIP2 (PRISM4) mid-Piacenzian (Pliocene) enhanced boundary conditions into the HadCM3 global climate model. We conducted PlioMIP2 CORE and tier 1 pre-industrial and Pliocene-based experiments as well as sensitivity ex- periments exploring solar insolation and orbit choice. We then examined the large-scale features of the atmosphere and ocean state of these experiments.

Compared to the pre-industrial control $\left(\mathrm{E}^{280}\right)$, we find Pliocene surface warming focussed within the high latitudes and whose spatial distribution is similar to that obtained with HadCM3 for PlioMIP1 under PRISM3 boundary conditions 
(Bragg et al., 2012). We find that the Pliocene palaeogeography and $400 \mathrm{ppm} \mathrm{CO}_{2}$ account for a warming (relative to the pre-industrial) in globally integrated MASAT (and MASST) of $1.4\left(0.8^{\circ} \mathrm{C}\right)$ and $1.5^{\circ} \mathrm{C}\left(1.0^{\circ} \mathrm{C}\right)$, respectively. We derive climate sensitivities of 3.5 and $2.9^{\circ} \mathrm{C}$ per doubling of $\mathrm{CO}_{2}$ for the pre-industrial and Pliocene, which are also similar to results from PlioMIP1 wherein they were estimated to be 3.3 and $3.1{ }^{\circ} \mathrm{C}$, respectively (Haywood et al., $2013 \mathrm{~b}$ ). We estimate the Earth system sensitivity at $\sim 5.6^{\circ} \mathrm{C}$, implying an ESS / CS ratio of $\sim 1.9$, which is similar to the ESS / CS ratio of 2.0 derived within PlioMIP1 (Haywood et al., 2013b). This similarity between PlioMIP1 and PlioMIP2 CS and the ESS / CS ratio demonstrates an insensitivity of these quantities to the degree of palaeogeographic variation between PlioMIP1 and PlioMIP2. This strongly indicates that the primary control on the ESS / CS ratio is the reconstructed ice distribution and global vegetation coverage which, with the exception to the Greenland Ice Sheet, is consistent between PlioMIP1 and PlioMIP2. The implementation of dynamic global vegetation models by PlioMIP2 participant groups will allow investigation of the sensitivity of ESS / CS to vegetation-climate feedbacks. We also recognise that CS and ESS calculations are model dependent and this will be looked at in detail in the multi-model comparison of PlioMIP2 results. Precipitation change is more complex. Pliocene geography is the primary driver of geographical distribution changes in precipitation, whilst both Pliocene geography and $\mathrm{CO}_{2}$ increase the globally integrated MAP.

We find an AMOC which is more intense in the Pliocene than in the pre-industrial, with the variation driven principally by the change in geography (Table 7). We determine this by comparing AMOC strength of $\mathrm{E}^{280}$ against Eoi $^{400}$ and Eoi $^{280}$. In addition, we have explored the sensitivity of AMOC strength to methodology applied for freshwater correction. The Eoi ${ }^{280}$ experiment uses a fixed freshwater correction field corresponding to pre-industrial iceberg trajectories, whilst the Pliocene experiment uses an annually derived correction (Sect. 2.2). In theory, this could impact on simulated AMOC intensity in $\mathrm{Eoi}^{400}$ vs. $\mathrm{E}^{280}$. To test this, we have conducted an additional $\mathrm{E}^{280}$ experiment using the annually derived freshwater correction methodology of $\mathrm{Eoi}^{400}$ (results not shown). This has demonstrated for the pre-industrial that the freshwater correction method does not lead to a statistically different AMOC strength. This indicates that our intensified AMOC within $\mathrm{Eoi}^{400}$ is indeed a consequence of palaeogeographic changes, rather than our approach to freshwater correction.

Both the choice of TSI (1361 vs. $1365 \mathrm{Wm}^{-2}$ ) and PRISM4 orbital configuration (modern vs. $3.205 \mathrm{Ma}$ ) have been shown not to significantly influence the anomaly-type analysis in use by the Pliocene community. For example, we show that the representation of the KM5c (3.205 Ma) time slice with a modern orbit is an acceptable choice - leading to no statistically significant differences within MASAT (Table 3) or MAP (Table 4), which is in accordance with pre- vious work (Haywood et al., 2013a). When considering absolute values or climatic indices, the influence of TSI or orbit is minimal but should nevertheless be considered. Models with greater climate sensitivity will present more sensitivity to TSI and potential for non-linearities in climate response (e.g. relating to feedbacks at or near the sea ice edge or climate-vegetation interactions).

Whilst the Pliocene represents an incredibly useful contemporary-climate analogue, the use of a non-modern palaeogeography (enhanced PRISM4 boundary condition dataset) does present limitations when using low to intermediate spatial resolution climate models. Regridding of the LSM to the $3.75^{\circ} \times 2.5^{\circ}$ model is imperfect due to the binary nature of the data and therefore requires manual corrections driven by an understanding of model architecture and physics (i.e. imposed by rigid-lid streamfunction, horizontal grid type, etc.). As a precursor, some a priori knowledge of important aspects of Pliocene ocean circulation is required to guide a series of expert-informed decisions on model configuration. Similarly, when model development teams (e.g. MOHC) create present-day boundary conditions, knowledge of circulation patterns and throughflow strength is often used to inform manual corrections (e.g artificial deepening of narrow channels) or the inclusion of parameterisations (e.g. diffusive pipes to represent, otherwise unrepresented, narrow straits). This a priori knowledge is not necessarily available for the Pliocene, and it is therefore difficult to assess. An example of this is in the subaerial extension of Ireland and Scotland within PRISM4, posing the question of how this region should be represented within the model and how the model representation may influence the simulation of the Norwegian Current. Additionally, the use of different model architectures and models with higher spatial resolution within the PlioMIP2 framework may allow these aspects to be considered. For example, free-surface ocean models with higher horizontal spatial resolution may help in the interpretation of the Pliocene ACC strength and the Pliocene Arctic Ocean cold anomaly identified within this study.

Palaeogeography-induced changes in mean state, for example, the path of the Antarctic Coastal Current around the peninsula island (Sect. 4.2.5), represent potentially nonanalogous characteristics imposed by the PRISM4 Pliocene reconstruction. Other non-analogous changes are associated with palaeogeographical changes to the maritime continent and subsequent changes in Indonesian throughflow configuration, the closure of the Bering Strait and Canadian Archipelago, and the withdrawal of the Baltic Sea and Hudson Bay. These palaeogeographical changes should be considered alongside those described within Hill (2015), such as the suggestion of extensive uplift in the Barents Sea (e.g. Knies et al., 2014) and the rerouting of major rivers (e.g. within North America), which may be currently unrepresented within the model. These important regional changes must be appreciated when considering the KM5c time slice 
as an equilibrium state analogue to contemporary-climate change (i.e. a 400 ppm world).

Data availability. Climatological averages within NetCDF4 files as specified by the PlioMIP2 experiment specifications are held at the University of Leeds data repository. Requests for access should be directed to Alan M. Haywood. Specific data requests should be sent to the lead author (s.hunter@leeds.ac.uk).

All PlioMIP2 boundary conditions are available on the USGS PlioMIP2 web page: http://geology.er.usgs.gov/egpsc/prism/7.2_ pliomip2_data.html (last accessed: 9 September 2019).

Author contributions. SJH, AMH and AMD designed the study. SJH developed the software framework and conducted the model setup, spin-up and all the data analysis. SJH and JCT developed model boundary conditions. SJH wrote the manuscript, generated figures and incorporated comments from co-authors. Correspondence and requests for materials should be addressed to $\mathrm{SJH}$.

Competing interests. The authors declare that they have no conflict of interest.

Special issue statement. This article is part of the special issue "PlioMIP Phase 2: experimental design, implementation and scientific results". It is not associated with a conference.

Acknowledgements. This work was undertaken on ARC3, part of the High Performance Computing facilities at the University of Leeds, UK. We acknowledge the contribution made by the University of Bristol in keeping the HadCM3 developed and updated. All boundary conditions were generated within a bespoke MATLAB framework using the MOHC-developed and National Centre for Atmospheric Sciences, Computing Modelling Services (NCAS-CMS)-supported xancil and um2nc tools (NCAS, 2019). Stephen J. Hunter is immensely grateful to two anonymous reviewers for their time and thoroughness. Their comments greatly improved the manuscript.

Financial support. This research has been supported by FP7 Ideas: European Research Council (grant no. PLIO-ESS, 278636) and the Past Earth Network (EPSRC grant no. EP/M008.363/1).

Review statement. This paper was edited by Wing-Le Chan and reviewed by two anonymous referees.

\section{References}

Archer, C. L. and Caldeira, K.: Historical trends in the jet streams, Geophys. Res. Lett., 35, L08803, https://doi.org/10.1029/2008GL033614, 2008.
Bonham, S. G., Haywood, A. M., Lunt, D. J., Collins, M., and Salzmann, U.: El Niño Southern Oscillation, Pliocene climate and equifinality, Philos. T. Roy. Soc. A, 367, 127-156, https://doi.org/10.1098/rsta.2008.0212, 2009.

Braconnot, P., Otto-Bliesner, B., Harrison, S., Joussaume, S., Peterchmitt, J.-Y., Abe-Ouchi, A., Crucifix, M., Driesschaert, E., Fichefet, Th., Hewitt, C. D., Kageyama, M., Kitoh, A., Laîné, A., Loutre, M.-F., Marti, O., Merkel, U., Ramstein, G., Valdes, P., Weber, S. L., Yu, Y., and Zhao, Y.: Results of PMIP2 coupled simulations of the Mid-Holocene and Last Glacial Maximum Part 1: experiments and large-scale features, Clim. Past, 3, 261277, https://doi.org/10.5194/cp-3-261-2007, 2007.

Bragg, F. J., Lunt, D. J., and Haywood, A. M.: Mid-Pliocene climate modelled using the UK Hadley Centre Model: PlioMIP Experiments 1 and 2, Geosci. Model Dev., 5, 1109-1125, https://doi.org/10.5194/gmd-5-1109-2012, 2012.

Bryan, K.: Climate and the Ocean Circulation, Mon. Weather Rev., 97, 806-827, 1969.

Bryan, K., Manabe, S., and Packanowski, R. C.: A global ocean-atmosphere climate model. II the oceanic circulation, J. Phys. Oceanogr., 5, 30-46, https://doi.org/10.1175/15200485(1975)005<0030:AGOACM>2.0.CO;2, 1975.

Burls, N. J., Fedorov, A. V., Sigman, D. M., Jaccard, S. L., Tiedemann, R., and Haug, G. H.: Active Pacific meridional overturning circulation (PMOC) during the warm Pliocene, Sci. Adv., 3, e1700156, https://doi.org/10.1126/sciadv.1700156, 2017.

Chandan, D. and Peltier, W. R.: Regional and global climate for the mid-Pliocene using the University of Toronto version of CCSM4 and PlioMIP2 boundary conditions, Clim. Past, 13, 919-942, https://doi.org/10.5194/cp-13-919-2017, 2017.

Chandler, M. A., Sohl, L. E., Jonas, J. A., Dowsett, H. J., and Kelley, M.: Simulations of the mid-Pliocene Warm Period using two versions of the NASA/GISS ModelE2-R Coupled Model, Geosci. Model Dev., 6, 517-531, https://doi.org/10.5194/gmd-6517-2013, 2013.

Cox, M.: A Primitive Equation, 3-dimensional Model of the Ocean, GFDL Ocean Group technical report, Geophysical Fluid Dynamics Laboratory/NOAA, Princeton University, 1984.

Cox, P. M., Betts, R. A., Bunton, C. B., Essery, R. L. H., Rowntree, P. R., and Smith, J.: The impact of new land surface physics on the GCM simulation of climate and climate sensitivity, Clim. Dynam., 15, 183-203, https://doi.org/10.1007/s003820050276, 1999.

Cunningham, S. A., Alderson, S. G., King, B. A., and Brandon, M. A.: Transport and variability of the Antarctic Circumpolar Current in Drake Passage, J. Geophys. Res.-Oceans, 108, 8084, https://doi.org/10.1029/2001JC001147, 2003.

Cusack, S., Slingo, A., Edwards, J. M., and Wild, M.: The radiative impact of a simple aerosol climatology on the Hadley Centre atmospheric GCM, Q. J. Roy. Meteor. Soc., 124, 2517-2526, https://doi.org/10.1002/qj.49712455117, 1998.

Dolan, A. M., Haywood, A. M., Hill, D. J., Dowsett, H. J., Hunter, S. J., Lunt, D. J., and Pickering, S. J.: Sensitivity of Pliocene ice sheets to orbital forcing, Palaeogeogr. Palaeoecl., 309, 98-110, https://doi.org/10.1016/j.palaeo.2011.03.030, 2011.

Dowsett, H. J., Foley, K. M., Stoll, D. K., Chandler, M. A., Sohl, L. E., Bentsen, M., Otto-Bliesner, B. L., Bragg, F. J., Chan, W.-L., Contoux, C., Dolan, A. M., Haywood, A. M., Jonas, J. A., Jost, A., Kamae, Y., Lohmann, G., Lunt, D. J., 
Nisancioglu, K. H., Abe-Ouchi, A., Ramstein, G., Riesselman, C. R., Robinson, M. M., Rosenbloom, N. A., Salzmann, U., Stepanek, C., Strother, S. L., Ueda, H., Yan, Q., and Zhang, Z.: Sea Surface Temperature of the mid-Piacenzian Ocean: A Data-Model Comparison, Sci. Rep.-UK, 3, 1-8, https://doi.org/10.1038/srep02013, 2013.

Dowsett, H., Dolan, A., Rowley, D., Moucha, R., Forte, A. M., Mitrovica, J. X., Pound, M., Salzmann, U., Robinson, M., Chandler, M., Foley, K., and Haywood, A.: The PRISM4 (midPiacenzian) paleoenvironmental reconstruction, Clim. Past, 12, 1519-1538, https://doi.org/10.5194/cp-12-1519-2016, 2016.

Essery, R. L. H., Best, M. J., Best, R. A., Cox, P. M., and Taylor, C. M.: Explicit Representation of Subgrid Heterogeneity in a GCM Land Surface Scheme, J. Hydrometeorol., 4, 530-543, https://doi.org/10.1175/15257541(2003)004<0530:EROSHI>2.0.CO;2, 2003.

Good, P., Jones, C., Lowe, J., Betts, R., and Gedney, N.: Comparing Tropical Forest Projections from Two Generations of Hadley Centre Earth System Models, HadGEM2-ES and HadCM3LC, J. Climate, 26, 495-511, https://doi.org/10.1175/JCLI-D-1100366.1, 2013.

Gordon, A. L. and Fine, R. A.: Pathways of water between the Pacific and Indian oceans in the Indonesian seas, Nature, 379, 146149, https://doi.org/10.1038/379146a0, 1996.

Gordon, C., Cooper, C., Senior, C. A., Banks, H., Gregory, J. M., Johns, T. C., Mitchell, J. F. B., and Wood, R. A.: The simulation of SST, sea ice extents and ocean heat transports in a version of the Hadley Centre coupled model without flux adjustments, Clim. Dynam., 16, 147-168, https://doi.org/10.1007/s003820050010, 2000.

Griesel, A., Mazloff, M. R., and Gille, S. T.: Mean dynamic topography in the Southern Ocean: Evaluating Antarctic Circumpolar Current transport, J. Geophys. Res.-Oceans, 117, C01020, https://doi.org/10.1029/2011JC007573, 2012.

Haywood, A. M., Dowsett, H. J., Otto-Bliesner, B., Chandler, M. A., Dolan, A. M., Hill, D. J., Lunt, D. J., Robinson, M. M., Rosenbloom, N., Salzmann, U., and Sohl, L. E.: Pliocene Model Intercomparison Project (PlioMIP): experimental design and boundary conditions (Experiment 1), Geosci. Model Dev., 3, 227-242, https://doi.org/10.5194/gmd-3-227-2010, 2010.

Haywood, A. M., Dowsett, H. J., Robinson, M. M., Stoll, D. K., Dolan, A. M., Lunt, D. J., Otto-Bliesner, B., and Chandler, M. A.: Pliocene Model Intercomparison Project (PlioMIP): experimental design and boundary conditions (Experiment 2), Geosci. Model Dev., 4, 571-577, https://doi.org/10.5194/gmd-4571-2011, 2011.

Haywood, A. M., Dolan, A. M., Pickering, S. J., Dowsett, H. J., McClymont, E. L., Prescott, C. L., Salzmann, U., Hill, D. J., Hunter, S. J., Lunt, D. J., Pope, J. O., and Valdes, P. J.: On the identification of a Pliocene time slice for datamodel comparison, Philos. T. Roy. Soc. A, 371, 20120515, https://doi.org/10.1098/rsta.2012.0515, 2013a.

Haywood, A. M., Hill, D. J., Dolan, A. M., Otto-Bliesner, B. L., Bragg, F., Chan, W.-L., Chandler, M. A., Contoux, C., Dowsett, H. J., Jost, A., Kamae, Y., Lohmann, G., Lunt, D. J., Abe-Ouchi, A., Pickering, S. J., Ramstein, G., Rosenbloom, N. A., Salzmann, U., Sohl, L., Stepanek, C., Ueda, H., Yan, Q., and Zhang, Z.: Large-scale features of Pliocene climate: results from the
Pliocene Model Intercomparison Project, Clim. Past, 9, 191-209, https://doi.org/10.5194/cp-9-191-2013, 2013b.

Haywood, A. M., Dowsett, H. J., Dolan, A. M., Rowley, D., Abe-Ouchi, A., Otto-Bliesner, B., Chandler, M. A., Hunter, S. J., Lunt, D. J., Pound, M., and Salzmann, U.: The Pliocene Model Intercomparison Project (PlioMIP) Phase 2: scientific objectives and experimental design, Clim. Past, 12, 663-675, https://doi.org/10.5194/cp-12-663-2016, 2016.

Hibler, W. D.: A Dynamic Thermodynamic Sea Ice Model, J. Phys. Oceanogr., 9, 815-846, https://doi.org/10.1175/15200485(1979)009<0815:ADTSIM>2.0.CO;2, 1979.

Hill, D. J.: The non-analogue nature of Pliocene temperature gradients, Earth Planet. Sc. Lett., 425, 232-241, https://doi.org/10.1016/j.epsl.2015.05.044, 2015.

Howell, F. W., Haywood, A. M., Dolan, A. M., Dowsett, H. J., Francis, J. E., Hill, D. J., Pickering, S. J., Pope, J. O., Salzmann, U., and Wade, B. S.: Can uncertainties in sea ice albedo reconcile patterns of data-model discord for the Pliocene and 20th/21st centuries?, Geophys. Res. Lett., 41, 2011-2018, https://doi.org/10.1002/2013GL058872, 2014.

Johns, T. C., Gregory, J. M., Ingram, W. J., Johnson, C. E., Jones, A., Lowe, J. A., Mitchell, J. F. B., Roberts, D. L., Sexton, D. M. H., Stevenson, D. S., Tett, S. F. B., and Woodage, M. J.: Anthropogenic climate change for 1860 to 2100 simulated with the HadCM3 model under updated emissions scenarios., Clim. Dynam., 20, 583-612, https://doi.org/10.1007/s00382-002-0296-y, 2003.

Kamae, Y., Yoshida, K., and Ueda, H.: Sensitivity of Pliocene climate simulations in MRI-CGCM2.3 to respective boundary conditions, Clim. Past, 12, 1619-1634, https://doi.org/10.5194/cp12-1619-2016, 2016.

Knies, J., Mattingsdal, R., Fabian, K., Grøsfjeld, K., Baranwal, S., Husum, K., Schepper, S. D., Vogt, C., Andersen, N., Matthiessen, J., Andreassen, K., Jokat, W., Nam, S.-I., and Gaina, C.: Effect of early Pliocene uplift on late Pliocene cooling in the Arctic-Atlantic gateway, Earth Planet. Sc. Lett., 387, 132-144, https://doi.org/10.1016/j.epsl.2013.11.007, 2014.

Koch, P., Wernli, H., and Davies, H. C.: An event-based jetstream climatology and typology, Int. J. Climatol., 26, 283-301, https://doi.org/10.1002/joc.1255, 2006.

Kopp, G. and Lean, J. L.: A new, lower value of total solar irradiance: Evidence and climate significance, Geophys. Res. Lett., 38, 5-48, https://doi.org/10.1029/2010GL045777, 2011.

Levitus, S. and Boyer, T. P.: World ocean atlas 1994. Vol. 4, Temperature, NOAA atlas NESDIS; 4, 1994.

Li, D. and Shine, K. P.: A 4-Dimensional Ozone Climatology for UGAMP Models, UGAMP Internal Report No. 35, available at: http://catalogue.ceda.ac.uk/uuid/ bff84b935ce5aa9f04624777b0eea507 (last access: 9 September 2019), 1995.

LSCE: PMIP2 Boundary Conditions, available at: https://pmip2. 1sce.ipsl.fr/design/boundary.shtml (last access: 14 April 2019), 2007.

Lunt, D. J., Valdes, P. J., Haywood, A., and Rutt, I. C.: Closure of the Panama Seaway during the Pliocene: implications for climate and Northern Hemisphere glaciation, Clim. Dynam., 30, 1-18, https://doi.org/10.1007/s00382-007-0265-6, 2008.

Matthes, K., Funke, B., Andersson, M. E., Barnard, L., Beer, J., Charbonneau, P., Clilverd, M. A., Dudok de Wit, T., Haber- 
reiter, M., Hendry, A., Jackman, C. H., Kretzschmar, M., Kruschke, T., Kunze, M., Langematz, U., Marsh, D. R., Maycock, A. C., Misios, S., Rodger, C. J., Scaife, A. A., Seppälä, A., Shangguan, M., Sinnhuber, M., Tourpali, K., Usoskin, I., van de Kamp, M., Verronen, P. T., and Versick, S.: Solar forcing for CMIP6 (v3.2), Geosci. Model Dev., 10, 2247-2302, https://doi.org/10.5194/gmd-10-2247-2017, 2017.

McCarthy, G. D., Smeed, D. A., Johns, W. E., Frajka-Williams, E., Moat, B. I., Rayner, D., Baringer, M. O., Meinen, C. S., Collins, J., and Bryden, H. L.: Measuring the Atlantic Meridional Overturning Circulation at $26^{\circ} \mathrm{N}$, Prog. Oceanogr., 130, 91-111, https://doi.org/10.1016/j.pocean.2014.10.006, 2015.

Meftah, M., Dewitte, S., Irbah, A., Chevalier, A., Conscience, C., Crommelynck, D., Janssen, E., and Mekaoui, S.: SOVAP/Picard, a Spaceborne Radiometer to Measure the Total Solar Irradiance, Sol. Phys., 289, 1885-1899, https://doi.org/10.1007/s11207013-0443-0, 2014.

Meijers, A. J. S., Shuckburgh, E., Bruneau, N., Sallee, J.-B., Bracegirdle, T. J., and Wang, Z.: Representation of the Antarctic Circumpolar Current in the CMIP5 climate models and future changes under warming scenarios, J. Geophys. Res.-Oceans, 117, C12008, https://doi.org/10.1029/2012JC008412, 2012.

National Geophysical Data Center: 5-minute Gridded Global Relief Data (ETOPO5), National Geophysical Data Center, NOAA, https://doi.org/10.7289/V5D798BF, 1993.

NCAS: Computational Modelling Services, Tools and Utilities, available at: http://cms.ncas.ac.uk/wiki/ToolsAndUtilities, last access: 14 April 2019.

Pardaens, A. K., Banks, H. T., Gregory, J. M., and Rowntree, P. R.: Freshwater transports in HadCM3, Clim. Dynam., 21, 177-195, https://doi.org/10.1007/s00382-003-0324-6, 2003.

Pope, V. D., Gallani, M. L., Rowntree, P. R., and Stratton, R. A.: The impact of new physical parametrizations in the Hadley Centre climate model: HadAM3, Clim. Dynam., 16, 123-146, https://doi.org/10.1007/s003820050009, 2000.

Prescott, C. L., Haywood, A. M., Dolan, A. M., Hunter, S. J., Pope, J. O., and Pickering, S. J.: Assessing orbitally-forced interglacial climate variability during the mid-Pliocene Warm Period, Earth Planet. Sc. Lett., 400, 261-271, https://doi.org/10.1016/j.epsl.2014.05.030, 2014.

Randall, D., Wood, R., Bony, S., Colman, R., Fichefet, T., Fyfe, J., Kattsov, V., Pitman, A., Shukla, J., Srinivasan, J., Ronald, S., Sumi, A., and Taylor, K.: Climate Models and Their Evaluation, in: Climate Change 2007: The Physical Science Basis. Contribution of Working Group I to the fourth Assessment Report of the Intergovernmental Panel on Climate Change, edited by: Solomon, S., Qin, M., Manning, Z., Marquis, M., Averyt, K. B., Tignor, M., and Miller, H., 589-662, Cambridge University Press, Cambridge, United Kingdom and New York, NY, USA, 2007.
Roether, W., Roussenov, V. M., and Well, R.: A Tracer Study of the Thermohaline Circulation of the Eastern Mediterranean, in: Ocean Processes in Climate Dynamics: Global and Mediterranean Examples, edited by: Malanotte-Rizzoli, P. and Robinson, A. R., 371-394, Springer Netherlands, Dordrecht, https://doi.org/10.1007/978-94-011-0870-6_16, 1994.

Semtner, A. J.: A model for the thermodynamic growth of sea ice in numerical investigations of climate, J. Phys. Oceanogr., 6, 379-389, https://doi.org/10.1175/15200485(1976)006<0379:AMFTTG>2.0.CO;2, 1976.

Stachnik, J. P. and Schumacher, C.: A comparison of the Hadley circulation in modern reanalyses, J. Geophys. Res.-Atmos., 116, D22102, https://doi.org/10.1029/2011JD016677, 2011.

Taylor, K. E., Stouffer, R. J., and Meehl, G. A.: An Overview of CMIP5 and the Experiment Design, B. Am. Meteorol. Soc., 93, 485-498, https://doi.org/10.1175/BAMS-D-11-00094.1, 2012.

Tindall, J. C. and Haywood, A. M.: Modeling oxygen isotopes in the Pliocene: Large-scale features over the land and ocean, Paleoceanography, 30, 1183-1201, https://doi.org/10.1002/2014PA002774, 2015.

Tribe, A.: Automated recognition of valley lines and drainage networks from grid digital elevation models: a review and a new method, J. Hydrol., 139, 263-293, https://doi.org/10.1016/00221694(92)90206-B, 1992.

USGS: Pliocene Model Intercomparison Project, Phase 2, available at: https://geology.er.usgs.gov/egpsc/prism/7_pliomip2.html (last access: 14 April 2019), 2016.

USGS: PMIP2 Model Data List, available at: https: //geology.er.usgs.gov/egpsc/prism/data/PlioMIP2_Model_ Data_List_updated2018.htm (last access: 14 April 2019), 2018.

Valdes, P. J., Armstrong, E., Badger, M. P. S., Bradshaw, C. D., Bragg, F., Crucifix, M., Davies-Barnard, T., Day, J. J., Farnsworth, A., Gordon, C., Hopcroft, P. O., Kennedy, A. T., Lord, N. S., Lunt, D. J., Marzocchi, A., Parry, L. M., Pope, V., Roberts, W. H. G., Stone, E. J., Tourte, G. J. L., and Williams, J. H. T.: The BRIDGE HadCM3 family of climate models: HadCM3@Bristolv1.0, Geosci. Model Dev., 10, 3715-3743, https://doi.org/10.5194/gmd-10-3715-2017, 2017.

Wilson, M. and Henderson-Sellers, A.: A global archive of land cover and soils data for use in General Circulation Climate Models, J. Climatol., 5, 119-143, https://doi.org/10.1002/joc.3370050202, 1985.

Zhang, Z.-S., Nisancioglu, K. H., Chandler, M. A., Haywood, A. M., Otto-Bliesner, B. L., Ramstein, G., Stepanek, C., Abe-Ouchi, A., Chan, W.-L., Bragg, F. J., Contoux, C., Dolan, A. M., Hill, D. J., Jost, A., Kamae, Y., Lohmann, G., Lunt, D. J., Rosenbloom, N. A., Sohl, L. E., and Ueda, H.: Mid-pliocene Atlantic Meridional Overturning Circulation not unlike modern, Clim. Past, 9, 1495-1504, https://doi.org/10.5194/cp-9-1495-2013, 2013. 